Discussion papers of the

Max Planck Institute for

Research on Collective Goods

Bonn 2019/11

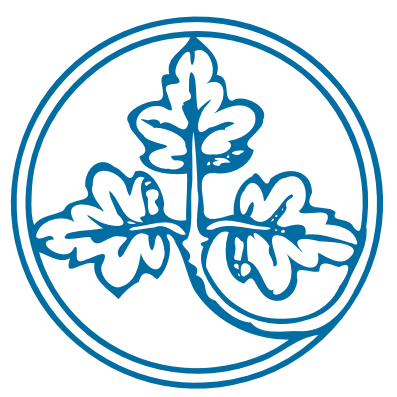

Transparency and Fairness in School Choice Mechanisms

Yoan Hermstrüwer

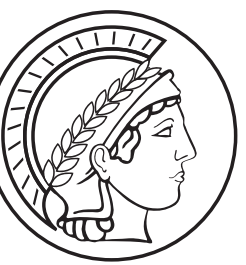




\title{
Transparency and Fairness in School Choice Mechanisms
}

\author{
Yoan Hermstrüwer
}

August 2019 


\title{
Transparency and Fairness in School Choice Mechanisms
}

\author{
Yoan Hermstrüwer*
}

\begin{abstract}
This article explores the impact of procedural information on the behavior of applicants under two of the most commonly used school admissions procedures: the Gale-Shapley mechanism and the Boston mechanism. In a lab experiment, I compare the impact of information about the mechanism, information about individually optimal application strategies, and information about both. I find that strategic and full information increase truth-telling and stability under the Gale-Shapley mechanism. Under the Boston mechanism, however, the adoption of equilibrium strategies remains unaffected. Contrary to prevailing assumptions in matching theory, I show that the Boston mechanism improves perceived fairness. These results underscore the importance of procedural information and suggest that eliminating justified envy may not be a sufficient condition of fairness.
\end{abstract}

JEL Codes: C78, C92, D47, I20, K10.

Keywords: matching markets, school choice, transparency, fairness, law and market design.

*Senior Research Fellow at the Max Planck Institute for Research on Collective Goods; Fellow at the Transatlantic Technology Law Forum, Stanford Law School, Stanford, CA. E-mail: hermstruewer@coll.mpg.de Address: Max Planck Institute for Research on Collective Goods, Kurt-Schumacher-Str. 10, 53113, Bonn, Germany. I would like to thank Phil Brookins, Christoph Engel, Lars Freund, Werner Güth, Svenja Hippel, Oliver Kirchkamp, Dorothea Kübler, Pascal Langenbach, Eugenio Verrina, Fabian Winter, and participants of the 3rd Workshop on Mechanism Design for Social Good Workshop (MD4SG '19) held in conjunction with the 20th ACM Conference on Economics and Computation (EC '19) in Phoenix for their valuable advice. Funding from the Max Planck Society is gratefully acknowledged. 


\section{Introduction}

One of the core challenges in the design of matching markets is to implement mechanisms that achieve stable outcomes and spur market participants to reveal their preferences truthfully. This is a particularly daunting task in matching markets, i.e. markets in which prices do not determine how resources are allocated. ${ }^{1}$ Many of the procedures used in matching markets are not secured against strategic manipulations. Accordingly, many participants have an incentive to manipulate their preferences in order to improve the outcome of the respective allocation procedure.

In the context of school choice, the problem of these mechanisms is that they provide an advantage to sophisticated applicants. These applicants are likely to belong to affluent or privileged households. Providing a strategic advantage to these applicants carries the risk of infringing upon constitutional equal protection rights and hampering efforts to facilitate social inclusion and promote equal opportunity. While legal scholars have pointed out that school choice is far from being a boon to fairness and autonomous choice (Ryan and Heise 2002; Minow 2011; Rauch 2015; Garnett 2017), most attempts to design fairer and more efficient assignment procedures have come from market designers. Many public school districts, including Boston (Abdulkadiroğlu et al. 2005), New Orleans (Abdulkadiroğlu et al. 2017), New York City (Abdulkadiroğlu, Pathak, and Roth 2005), Philadelphia, and Washington, D.C. have benefited from the "market design revolution" by adopting assignment procedures that are strategy-proof and designed to produce stable outcomes. ${ }^{2}$

The core idea underlying the adoption of these mechanisms is to create a level

1. Matching markets include school choice procedures (Abdulkadiroğlu and Sönmez 2003), kidney exchange procedures (Roth, Sönmez, and Ünver 2004), or the resettlement of refugees (Delacrétaz, Kominers, and Teytelboym 2016). For an overview of law and market design as a discipline, see Posner and Weyl (2018).

2. Strategy-proofness is a synonym for incentive compatibility and means that it is not possible to game the mechanism by not revealing preferences truthfully. Stability means that there is no pair of student and school that is not matched with each other but would prefer to be matched with each other. The normative virtue of stability is that it prevents a systematic violation of school priorities and eliminates justified envy among students. 
playing field for students and prevent the potentially discriminatory effects engendered by non-strategy-proof mechanisms, the most prominent example being the Boston (BOS) mechanism used by Boston Public Schools until 2005 (Abdulkadiroğlu 2013). ${ }^{3}$ The problem is that individuals tend to manipulate their preferences even when mechanisms are strategy-proof. While participants on at least one side of the market can safely reveal their true preferences under the Gale-Shapley (GS) mechanism (Gale and Shapley 1962) and the Top Trading Cycles (TTC) mechanism (Shapley and Scarf 1974), evidence for attempts to game these mechanisms has been documented in various lab experiments (Chen and Sönmez 2006; Pais and Pintér 2008; Calsamiglia, Haeringer, and Klijn 2010; Klijn, Pais, and Vorsatz 2013). The static GS mechanism, in which applicants make a single decision (i.e. submit a complete rank-order preference list), is particularly vulnerable to preference manipulations, but it remains widely used in practice (Klijn, Pais, and Vorsatz 2019). Accordingly, recent empirical evidence suggests that physicians manipulate their preferences under the National Resident Matching Program (NRMP), one of the most prominent implementations of a strategy-proof assignment procedure in the US (Rees-Jones and Skowronek 2018).

Considering the substantial efforts put into implementing strategy-proof mechanisms, it is quite remarkable that students attempt to game the system when there is nothing to be gamed. ${ }^{4}$ One potential explanation is that knowing the rules may not be the same as understanding the rules. On the one hand, cognitive abilities are likely to determine whether students adopt an adequate strategy (see Basteck and Mantovani 2018). On the other hand, it is far from clear whether the fairness of a mechanism should be assessed based on its allocative or incentive properties (Kamada and Kojima 2019) rather than on its transparency. Perhaps most importantly, it is not clear whether matching mechanisms can work properly without providing comprehensible procedural information (see Pathak 2017;

3. A detailed explanation of the Boston mechanism and the Gale-Shapley mechanism can be found in Section 3.

4. In many countries, there is an industry that sells advice on adequate application strategies to parents and applicants. This industry has an incentive to uphold the opacity of existing application procedures and exploit it for commercial profit. 
Rees-Jones 2017; Guillen and Hakimov 2018). Tackling this conundrum, I address the following questions: What kind of procedural information do students exactly need to make better school choices, how do cognitive abilities affect these choices, and what is the impact of procedural information on the perceived fairness of the assignment procedure?

To investigate these questions, I conduct an experiment designed to identify the effects of three different information environments under two of the most commonly used mechanisms: the student-proposing GS mechanism and the BOS mechanism. Under the student-proposing GS mechanism, students are incentivized to reveal their preferences truthfully. Under the BOS mechanism, students are incentivized to adopt two different dropping strategies, depending on their type. Students of the first type have an incentive to manipulate their top choice and rank a less preferred school as first choice on their rank-order list (skip-the-top). Students of the second type have an incentive to manipulate their second choice and rank a less preferred as second choice on their rank-order list while upholding their top choice (skip-themiddle). In the first environment, students only receive information about the rules of the assignment procedure (baseline). This treatment is designed to increase the salience of the equilibrium strategy and dampen the effect of false inferences about adequate strategies. In the second environment, students only receive information about the equilibrium strategies under the respective mechanism without an explanation of the procedure (strategic information). While students are told that acting strategically will never be beneficial under the GS mechanism, they receive type-specific information about equilibrium strategies under the BOS mechanism. In the third environment, students receive full procedural information both about the procedure and the respective equilibrium strategies (combined information). This treatment mimicks the practice adopted by several US public school districts (that use the GS or the TTC mechanism and tell students not to strategize) and the German clearinghouse in charge of university admissions (that partly uses the BOS mechanism and tells students how to strategize).

I find that truth-telling rates do not significantly differ between the GS and the BOS mechanism in the baseline treatment. Under the GS mechanism, strate- 
gic and combined information strongly increase truth-telling rates as compared to the baseline treatment. Truth-telling rates do not significantly differ between the strategic and the combined information treatments. Under the BOS mechanism, the strategic and the combined information treatments have a negative effect on truth-telling but no positive effect on the adoption of equilibrium strategies. While the frequency of stable matchings is extremely low (approximately $30 \%$ ) in the GS baseline treatment, the strategic and combined information treatments significantly and strongly increase stability under the GS mechanism (100\% and 87.50 $\%)$. Moreover, cognitive reflection abilities facilitate sensible strategies only for students facing a particularly complex strategic problem, i.e. those students who can improve their matching by adopting a skip-the-middle strategy. Finally, my fairness measures yield results that may hint at a conundrum in law and market design: fairness assessments are not higher under the GS mechanism. Rather, my results suggest that strategic and combined information under the BOS mechanism have a positive impact on perceived outcome fairness.

While this is the first study to investigate the relationship between different kinds of procedural information, cognitive abilities and fairness, it is closely related to a growing strand in the literature on school matching markets. There is some evidence that combining a thorough explanation of the mechanism with strategic advice in the German university admissions procedure increases truth-telling (Braun et al. 2014). However, the authors of that study use advice as a robustness check under a non-strategy-proof mechanism, whereas my study is intended to isolate the effect of different information environments across different mechanisms, measure the role of cognitive abilities, and elicit fairness assessments. In an investigation of the TTC mechanism, Guillen and Hing (2014) observe higher truth-telling rates when applicants receive correct strategic advice, and lower truthtelling rates when strategic advice is wrong. Similarly, Guillen and Hakimov (2018) find that descriptions of strategy-proofness entail higher truth-telling rates under the TTC mechanism, while descriptions of the mechanism decrease truth-telling rates. Finally, Ding and Schotter $(2017,2019)$ show that inter-generational advice and chatting through social networks have a positive effect on strategies, welfare 
and stability under the GS mechanism and the BOS mechanism. However, non of these studies explores the impact of controlled strategic information on the behavior of different types of applicants, stability, and perceived fairness in a comparison of a strategy-proof and non-strategy-proof mechanisms.

My study also relates to other strands in the literature on matching markets. Evidence suggests that truth-telling is sensitive to seemingly innocuous changes of the choice structure. Restricting the admissible number of schools on a rank-order list, for example, may prompt students to manipulate their preferences (Haeringer and Klijn 2009; Calsamiglia, Haeringer, and Klijn 2010). ${ }^{5}$ In addition, there is a growing experimental literature that explores whether a dynamic implementation of the GS mechanism may improve applicants' comprehension of the assignment procedure. A dynamic implementation follows a step-by-step procedure, in which students sequentially reveal their preferences after each rejection. Exploring a dynamic implementation of the GS mechanism, Echenique, Wilson, and Yariv (2016) find that proposers do not submit offers that reflect their true preference orderings (i.e. skip potential partners) and that less than $50 \%$ of the markets yield a stable matching. Klijn, Pais, and Vorsatz (2019) show that the dynamic student-proposing GS mechanism slightly outperforms the static implementation with respect to truth-telling, stability and efficiency. By contrast, the results presented in this article suggest that strategic information may compensate for the weaknesses associated with static mechanism implementations.

Furthermore, evidence indicates that the choices made under matching mechanisms are sensitive to variations in the information structure. While the GS mechanism outperforms the TTC mechanism in truth-telling under incomplete information about the preferences of other applicants (Chen and Sönmez 2006), the opposite can be observed in complete information environments (Chen, Liang, and Sönmez 2016). Truth-telling has been shown to decrease when applicants ob-

5. The intuition is fairly simple: If the number of acceptable schools exceeds the number of schools that can be included in the rank-order list, students may be afraid of being rejected at their most preferred school and thus "wasting" a choice. To prevent this risk, students may be better off by skipping preferred schools and including less preferred schools in their rank-order list. 
tain more information about other students' preferences (Pais and Pintér 2008; Pais, Pintér, and Veszteg 2011) or other students' strategies (Guillen and Hakimov 2017). However, recent experimental evidence also suggests that applicants adopt the truth-telling strategy too frequently when they would be better off by adopting a specific truncation strategy under the GS mechanism (Featherstone and Mayefsky 2015). My study takes a different approach in that I manipulate information about the rules of the respective mechanism rather than information about preferences or strategies.

Finally, there is some evidence that the outcome of a matching mechanism depends on risk preferences and personality traits. For example, Klijn, Pais, and Vorsatz (2013) find evidence that, under the GS mechanism, truth-telling drops as risk aversion increases, while Basteck and Mantovani (2018) show that students with lower cognitive abilities fail to strategize well under the BOS mechanism, which entails lower payoffs and over-representation at low-ranked schools. This article contributes to this literature by showing that the relevance of cognitive abilities depends on the complexity of the strategy required to achieve an individually optimal outcome.

The remainder of this article is organized as follows. In Section 2, I discuss the legal background. Section 3 presents a brief summary of the theory. Section 4 describes my experimental design and predictions. Section 5 reports the results of the experiment. Section 6 concludes.

\section{Remedies to procedural opacity in school choice}

The remedies to tackle the problem of complex school choice procedures differ across jurisdictions. While many US public school districts have simplified their assignment procedures by adopting the GS mechanism (Section 2.1), other countries, including Germany, cling to assignment procedures based on the BOS mechanism and try to increase the transparency of their deficiencies (Section 2.2). 


\subsection{Designing simplicity: The US example}

In the US, school choice refers to an explicit administrative framework backed by constitutional law that grants parents and applicants the right to select from a menu of schools and rank these schools according to their preferences. The idea of parental choice came up in the context of religious freedom at the time of Pierce v. Society of Sisters [268 U.S. 510, 535 (1925)]. Yet the idea of school choice as a means to foster civil rights only gained traction in the wake of Brown v. Board of Education [347 U.S. 483 (1954)]. This hallmark decision not only marked a turning point towards school choice policies intended to promote racial desegregation and equal opportunity (Minow 2010; Hitzig, forthcoming). It can also be considered the embodiment of liberal and utilitarian values, i.e. of autonomy or the more market-oriented conception of consumer sovereignty (Minow 2011). The idea of free choice coupled with public funding of schools was prominently endorsed by Milton Friedman (Friedman 1962). In the spirit of this liberal turn, the Supreme Court eventually upheld a voucher system designed to support poor families in school choice procedures (Zelman v. Simmons Harris [536 U.S. 639 (2002)]).

Despite this evolution of constitutional jurisprudence and a rigorous interpretation of the Equal Protection Clause enshrined in the Fourteenth Amendment (see Mead and Lewis 2016), ${ }^{6}$ school choice remains vulnerable. One of the most important problems is the complexity of admissions criteria and assignment procedures. Many parents and applicants, especially those with a less advantaged socio-economic background, do not have the information that is necessary to engage in strategic considerations and make sensible choices (Ryan and Heise 2002; Minow 2011). While access to information and simple assignment procedures are crucial to create a level playing field, courts have avoided taking a clear position on these issues (see Parents Involved v. Seattle School District No. 1 [551 U.S. $701(2007)])$.

The first move to address concerns about transparency and fairness in assignment procedures came from the Boston School Committee in 2005. The Boston

6. The Equal Protection Clause is the main source of constitutional non-discrimination doctrine at the federal level. 
Public Schools had previously used the BOS mechanism - a mechanism that involves the immediate acceptance of student applications by schools and is therefore vulnerable to strategic manipulations (Abdulkadiroğlu et al. 2005). Students anticipating that they would have low chances of being admitted at their first choice school, could improve their chances of being admitted at their second choice school by ranking it first. Students who would not strategize and rank schools according to their true preferences, incurred the risk of losing their priority to strategizing students. This assignment procedure harmed parents who did not strategize well.

In order to eliminate the incentives to game the system and create a level playing field, the Boston Public Schools eventually adopted the student-optimal stable GS mechanism. Many other public school districts, including New York City, Chicago and Cleveland, followed and abolished assignment procedures based on the BOS mechanism (Pathak and Sönmez 2013). In England, assignment procedures based on the BOS mechanism - procedures using the first-preferences-first criterion - were first outlawed in 2007 (Pathak and Sönmez 2013). Under Section 1.9.c) of the 2014 School Admissions Code, first-preferences-first remains outlawed as an oversubscription criterion in England. ${ }^{7}$

The problem of these reforms is that they are incomplete. School choice requires informed decisions. Yet the mere introduction of strategy-proof mechanisms may be insufficient to create a level playing field if parents and applicants do not understand the incentives set by the assignment procedure. Nudging parents through default options is not the only solution to this problem (Rauch 2015). In fact, it is far from clear whether nudges that do not provide specific information actually enable parents to make informed decisions at all. To mitigate the problem of incomplete information, many US public school districts using strategy-proof procedures provide specific information about the strategic implications of the assignments procedures used. More specifically, applicants are told that attempts to game the assignment procedure by not ranking schools according to their true preferences are not individually beneficial.

7. See <https://www.gov.uk/government/publications/school-admissions-code-2>, last accessed on August 5, 2019. 
The Office of the State Superintendent of Education in the District of Columbia, for example, provides the following information:

"Developed specifically for My School DC by the Institute for Innovation in Public School Choice (IIPSC), the lottery is based on the Nobel Prize-winning work of economist Al Roth of Stanford University. (...) The two most important things to know about the program are: 1) Students should rank schools in the order they like most to increase their chances of being matched to their desired school. 2) Students who apply early get no advantage in the matching process. (...) This is why the system is strategy-proof - and why students are best served by ranking schools according to their true choices." 8

The Office of Access and Enrollment in the Chicago Public Schools System provides comparable procedural information:

"The selection process is designed to offer the student the highest possible choice on their application that they are qualified for and where there are available seats. It is EXTREMELY IMPORTANT for you to list the schools/programs on the application in the ORDER OF YOUR CHOICE. You will list the program you want MOST as your first choice, the program you want next as your second choice, and so on. This is the order in which the student will be considered."9

Not all public school districts using strategy-proof assignment procedures provide procedural information (an overview of information provided by other public school districts can be found in Appendix A.1.). And even those that do, often do not make it very salient. This is likely to work to the detriment of uninformed or unsophisticated parents and applicants who do not know where to search for procedural information in the first place. It is therefore not clear what the impact of procedural information is, especially when search costs are high. Furthermore,

\footnotetext{
8. See <https://www.myschooldc.org/faq/faqs >, last accessed on August 5, 2019.

9. See <https://cps.edu/AccessAndEnrollment/Pages/OAE.aspx $>$, last accessed on August
} $5,2019$. 
even if parents and applicants end up stumbling over the information, it is questionable whether they will trust it and rank schools accordingly. ${ }^{10}$

\subsection{Explaining complexity: The German example}

The German university admissions procedure for medical school illustrates the economic and legal problems of non-strategy-proof matching mechanisms (Westkamp 2013; Braun, Dwenger, and Kübler 2010; Braun et al. 2014). The tools to reduce the adverse impact of complexity and facilitate sensible choices when submitting rank-order lists over universities are therefore quite different from those discussed in the context of school choice in the US. Rather than telling students not to strategize, the university admissions clearinghouse (Stiftung für Hochschulzulassung) tells students how to strategize. The reason for pointing students at the possibility of gaming the admissions procedure mainly stems from the implementation of two sequential mechanisms.

The first mechanism is centralized and operated by the university admissions clearinghouse (centralized mechanism). The objective of the centralized mechanism is to provide an advantage to top students and increase their chances of being admitted to a university of their preferred choice. To achieve this objective, university admissions law sets a top student quota. ${ }^{11}$ According to the Constitutional Court, considering high school grades as the main admissions criterion in the centralized mechanism is compatible with the freedom of profession and the right to equal protection under Art. 12 Sec. 1 and Art. 3 Sec. 1 of the German Constitution (BVerfG, December 19, 2017 - 1 BvL 3/14, 1 BvL 4/14, paras. 127-138). ${ }^{12}$ Students are ranked according to their high school grade from best

10. The same problem arose when designing the 2017 FCC spectrum auction. While the market designers in charge considered using a Vickrey auction, they eventually refrained from using it, because they feared that bidders would not trust explanations that bidding true valuations is a dominant strategy (Milgrom and Tadelis 2019).

11. The student quota serves to determine the number of eligible students based on a cutoff in the average high school grades (numerus clausus).

12. Before 2018, the clearinghouse considered both high school grades and geographic preferences in the admissions criteria. Students who were not admitted at the university they had 
to worst. Eligible students are selected according to their rank on the grade-order list until the number of selected students is equal to the number of seats in the top student quota. Finally, students are assigned to seats using the BOS mechanism.

The second mechanism is decentralized and operated by the universities once the first mechanism has been implemented (university mechanism). The objective of the university mechanism is to increase the chances of all remaining students of being admitted at their preferred university. To achieve this objective, each university sets a quota (residual quota). Students are ranked according to the priorities determined by each university. While admissions criteria vary across universities, most weight is usually given to high school grades. The pool of eligible students includes both top students who were not assigned a seat in the centralized mechanism and the remaining students. Top students who were assigned a seat in the centralized mechanism do not participate in the second mechanism. All top students are allowed to submit two different rank-order lists - one for each mechanism -, since they can be assigned a seat both in the centralized and in the university mechanism. Eligible students are selected according to university priorities until all seats available under the residual quota have been assigned. Finally, students are assigned to seats using the university-proposing GS mechanism. ${ }^{13}$

The problem of this sequential procedure is that it is highly vulnerable to gaming. Since the admissions procedure consists of two different mechanisms, top students have to consider their chances of being admitted under each mechanism. If top students submit a long rank-order list in the centralized mechanism, they run the risk of being matched with a university that is low on their rank-order list, while

ranked first on their rank-order list, ran the risk of not being admitted at the universities with a lower rank on their rank-order list if competing students had ranked these universities on top of their rank-order list. Students who were not assigned a seat at their first choice had therefore lower chances of being admitted under the top student quota even if they had better high school grades than competing students. The Constitutional Court declared that this procedure is unconstitutional (see BVerfG, December 19, 2017 - 1 BvL 3/14, 1 BvL 4/14, paras. 134-137). 13. Under the university-proposing GS mechanism, universities submit offers to students. Under the student-proposing GS mechanism investigated in this article, students submit applications to universities. For the proposing side of the matching market, the GS mechanism is strategyproof and yields the best stable matching. 
they could have been matched with a more preferred university in the university mechanism (Braun, Dwenger, and Kübler 2010; Westkamp 2013). ${ }^{14}$ Therefore, top students can improve their chances of being matched with one of their preferred universities if they truncate their rank-order list for the centralized mechanism by ranking only a few top choices.

The Constitutional Court's decision does not consider this incentive problem. It even seems at odds with the logic of the admissions procedure and the incentives for students to misreport their preferences. Before 2018, rank-order lists were restricted to six universities under the centralized mechanism. The Constitutional Court considered that this restriction constitutes a violation of the fundamental rights granted under Art. 12 Sec. 1 and Art. 3 Sec. 1 of the German Constitution (BVerfG, December 19, 2017 - 1 BvL 3/14, 1 BvL 4/14, para. 138). From a matching perspective, this extension of freedom runs counter to the truncation incentives set by the procedure. Since students should rank less than six universities in the centralized mechanism, extending the freedom to rank universities can be seen as basically useless.

While the Constitutional Court declared that the restriction of rank-order lists to six universities is unconstitutional under the centralized mechanism, it upheld a similar restriction applying to the university mechanism (BVerfG, December 19, 2017 - $1 \mathrm{BvL} 3 / 14,1 \mathrm{BvL} 4 / 14$, paras. 159-163). It is striking that this restriction was maintained for reasons of procedural efficiency. From a matching perspective, stability and strategy-proofness are at risk whenever such constraints are imposed: When the number of universities that may be included in a rankorder list is restricted, ranking universities truthfully may not be safe for students who have more than six acceptable universities, even if the mechanism is strategyproof in principle (Haeringer and Klijn 2009; Calsamiglia, Haeringer, and Klijn 2010). Students who fear being rejected by their preferred university may therefore uprank a less preferred university on their rank-order list to increase their

14. In addition, the matching would be unstable if a preferred university would also prefer to be matched with the top student who was assigned a seat under the centralized mechanism rather than with a student it was matched with under the university mechanism. 
chances of getting an acceptable offer - a problem that is even more acute when the preferences of other students are unknown.

To facilitate the strategic considerations that students need to grapple with, the clearinghouse provides explicit information about some of the strategic implications of the procedure by telling top students how they can benefit from manipulating their rank-order lists. More specifically, top students are told that they should consider truncating their rank-order list in the centralized mechanism and only rank the most preferred universities. ${ }^{15}$ Students who do not strategize accordingly incur the risk of foregoing a preferred seat under the university mechanism. However, it is not clear whether procedural information can effectively compensate the inequalities between sophisticated and unsophisticated students arising from the use of non-strategy-proof mechanisms. While this article does not explore information about a truncation strategy, it follows the general spirit of the German practice and investigates the impact of information about a dropping strategy.

\section{Theory}

A school choice problem is set up as follows. There is a non-empty finite set of students $I=\left\{i_{1}, i_{2}, \ldots, i_{n}\right\}$ and a non-empty finite set of schools $U=\left\{u_{1}, u_{2}, \ldots, u_{n}\right\}$. Each student $i$ has a strict preference ordering $\succ_{i}$ over schools and being unmatched $U \cup\{\emptyset\}$, where $\emptyset$ stands for being unmatched and $\succ_{I}=\left\{\succ_{i_{1}}, \succ_{i_{2}}, \ldots, \succ_{i_{n}}\right\}$ denotes the profile of all student preference orderings. Each school $u$ has a strict priority ordering $\succ_{u}$ over students, where $\succ_{U}=\left\{\succ_{u_{1}}, \succ_{u_{2}}, \ldots, \succ_{u_{n}}\right\}$ denotes the

15. "Unter Umständen ist es sinnvoll, wenn Sie in der Abiturbestenquote nicht alle sechs möglichen Ortswünsche angeben, sondern sich auf die Hochschulen beschränken, an denen Sie auch tatsächlich das Studium aufnehmen möchten. Nennen Sie beispielsweise in der Abiturbestenquote nur eine Hochschule, kann es zwar passieren, dass Sie an dieser Hochschule nicht ausgewählt werden. Sie haben aber die Möglichkeit, im zeitlich später durchgeführten Auswahlverfahren der Hochschulen eventuell an dieser Hochschule zugelassen zu werden, da oft die Auswahlkriterien günstiger sind als in der Abiturbestenquote." See $<$ https://zv.hochschulstart.de/index.php?id=281>, last accessed on August 5, 2019. 
profile of priority orderings over students. Each school $u$ has a capacity $q_{u}>0$. The school choice problem is given by $P=\left(\succ_{I}, \succ_{U}\right)$. A matching is a mapping $\mu: I \rightarrow U$ from students to schools. The mapping specifies which student is assigned to which school, where $\mu_{u} \subseteq I$ and $\mu_{i} \in U \cup\{\emptyset\}$. The matching $\mu_{i_{1}}=u_{1}$ indicates that student $i_{1}$ is matched to school $u_{1}$, while the matching $\mu_{u_{1}}=i_{1}$ denotes that school $u_{1}$ is matched to $i_{1}$. A matching $\mu$ that assigns $i_{1}$ to $u_{1}, i_{2}$ to $u_{2}, i_{3}$ to $u_{3}$, and $i_{n}$ to $u_{n}$ is given by:

$$
\mu=\left(\begin{array}{cccc}
i_{1} & i_{2} & i_{3} & i_{n} \\
u_{1} & u_{2} & u_{3} & u_{n}
\end{array}\right)
$$

The three core properties that most matching mechanisms seek to achieve are efficiency, stability and strategy-proofness. Efficiency and stability refer to the allocative properties of the matching.

A matching is efficient if there is no $\mu^{*}$ so that $\mu^{*} \succeq_{i} \mu_{i}$ for all $i \in I$ and $\mu^{*} \succ_{i} \mu_{i}$ for at least one $i \in I$, i.e. if there is no other matching that all students weakly prefer over their current matching and at least one student strictly prefers over her current matching. Note that the concept of efficiency - unlike the concept of stability - only considers the preferences of students.

A matching $\mu_{i}$ is stable if it is individually rational, non-wasteful and envyfree. First, the rationality condition is satisfied if $\mu_{i} \succeq_{i} \emptyset$ for all $i \in I$, i.e. if no student strictly prefers to remain unmatched over her current matching. Second, a matching is non-wasteful if $u \succ_{i} \mu_{i}$, then $\left|\mu_{u}\right|=q_{u}$ for all $i \in I$, i.e. if a student prefers another school to her current matching, this school must have exhausted its capacity. Third, a matching eliminates justified envy if there is no pair $(i, u)$, where $u \succ_{i} \mu_{i}$ and $i \succ_{u} \mu_{u}$ for all $i \in I$ and all $u \in U$, i.e. there is no pair of a student and a school that is not matched with each other but would prefer to be matched with each other (no blocking pair).

Strategy-proofness refers to the incentives set by the matching mechanism rather than the allocative properties of the matching. Accordingly, a mechanism $\varphi$ is strategy-proof for students if $\varphi_{I}\left(\succ_{I}, \succ_{-I}\right) \succeq_{i} \varphi_{I}\left(\succ_{I}^{\prime}, \succ_{-I}\right)$ for all $i \in I, \succ_{I}, \succ_{I}^{\prime}$ ,$\succ_{-I}$. This means that no student has an incentive to misreport her preferences, 
regardless of how other students report their preferences.

While all properties can be seen as normatively desirable, two are of particular relevance in the legal context of this article. On the one hand, a stable matching prevents the violation of school priorities and eliminates justified envy among students. Since no pair of a student and a school has an incentive to deviate from the existing matching, stability is usually assumed to eliminate the threat of appeals and lawsuits (Abdulkadiroğlu, Pathak, and Roth 2005). Specifically, the existence of blocking pairs may be conceptualized as an infringement upon equal protection rights, depending on the legal requirements for the right to bring an action to court (locus standi) and the burden imposed on plaintiffs to prove an injury resulting from an assignment procedure (Ehlers and Morrill 2018). On the other hand, strategy-proofness makes sure that the outcome generated by the mechanism does not depend on the strategic sophistication of students. Hence, it is impossible for students to game the procedure by manipulating their rank-order lists.

On a normative view, both stability and strategy-proofness can be conceptualized as criteria of two different kinds of fairness. It is important to note that the respective fairness notions are derived from specific allocative and incentive properties without necessarily reflecting actual fairness sentiments. If the outcome produced by the matching mechanism eliminates justified envy, stability can be said to foster outcome fairness (Balinski and Sönmez 1999; Kamada and Kojima 2019). This idea is in line with fairness notions that prominently feature in distributive justice theories, where - given an initially equal distribution of buying power - the absence of envy indicates the equal satisfaction of preferences of all citizens (Elster 1992; Dworkin 1981, p. 285). If the rules of the matching mechanism do not provide any advantage to sophisticated students, strategy-proofness can be said to foster procedural fairness (Pathak and Sönmez 2008). Specifically, strategy-proofness embodies an egalitarian fairness notion, as (i) the revelation of preferences is completely independent from the allocation procedure imposed on citizens (Dworkin 1981, p. 290) and (ii) the final allocation of resources is not determined by the initial distribution of strategic abilities in society. 


\subsection{Gale-Shapley mechanism}

The student-proposing GS mechanism proposed by Gale and Shapley (1962) proceeds as follows:

In the first step, each student applies to her preferred university. Each university tentatively admits students in the order of the university's priority rankings until the capacity is exhausted or no acceptable students are left. All other students are rejected, the rejection being final.

In the $k$-th step, each student rejected in $k-1$ applies to her most preferred university on the rank-order list of universities that have not rejected her before. If no university is left on the rank-order list, the student applies nowhere. Each university considers the offers on hold from previous steps and new offers. Each university tentatively admits students in the order of the university's priority ranking until the remaining capacity is exhausted or no acceptable students are left. All other students are rejected, the rejection being final.

The algorithm ends when no more rejections are issued. Each university is matched to the students it is holding.

The student-proposing GS mechanism features two well-known properties. On the one hand, the GS mechanism results in a stable matching (Gale and Shapley 1962). This matching is student-optimal, because it is the most preferred stable matching for students and the least preferred stable matching for schools (Dubins and Freedman 1981). On the other hand, the GS mechanism is strategy-proof for proposing students, with truth-telling being a weakly dominant strategy (Dubins and Freedman 1981; Roth 1982). ${ }^{16}$

\subsection{Boston mechanism}

The BOS mechanism (Abdulkadiroğlu and Sönmez 2003; Abdulkadiroğlu et al. 2005; Ergin and Sönmez 2006) proceeds as follows:

16. Roth (1982) shows that no stable matching mechanism is strategy-proof for both sides of the market. 
In the first step, each student applies to her preferred university. Each university immediately admits students in the order of the university's priority ranking until the capacity is exhausted or no acceptable students are left. All other students are rejected, the rejection being final. Each admitted student becomes a permanent match. The capacities of each university are adjusted to account for students admitted in this step.

In the $k$-th step, each student rejected in $k$-1 applies to her most preferred university on the rank-order list of universities that have not rejected her before. If no university is left on the rank-order list, the student applies nowhere. Each university immediately admits students in the order of the university's priority ranking until the remaining capacity is exhausted or no acceptable students are left. All other students are rejected, the rejection being final. Each admitted student becomes a permanent match. The capacities of each university are adjusted to account for students admitted in this step.

The algorithm ends when no more rejections are issued.

In contrast to the GS mechanism, the BOS mechanism can be considered an immediate acceptance mechanism (Featherstone and Niederle 2016). While acceptance is deferred to the very end of the procedure under the GS mechanism, it is immediate under the BOS mechanism. This is why the BOS mechanism is not strategy-proof: If a university admits a student early in the procedure and exhausts its capacities, it incurs the risk of being unable to admit higher-priority students in later steps of the procedure (priority violation).

\section{Experimental design}

\subsection{Basic setup}

The experiment is designed to identify the effects of three different information environments under the student-proposing GS mechanism and the BOS mechanism 
( $2 \times 3$ factorial design). ${ }^{17}$ The setup used in the two baseline treatments of my experiment closely follows the framework used by Featherstone and Niederle (2016). ${ }^{18}$ There are four universities $u \in U=\{A, B, C, D\}$, five students $s \in S=\left\{s_{1}, \ldots, s_{5}\right\}$ and two student types $t \in T=\left\{t_{1}, t_{2}\right\}$. There are three Type- 1 students and two Type-2 students. ${ }^{19}$ According to the quota rule, two seats are available at university $A$, while university $B, C$ and $D$ offer one seat each.

Student preferences over schools are induced exogenously and aligned. Accordingly, each student receives 100 points for being matched with $A, 67$ points for being matched with $B, 25$ points for being matched with $C$, and 0 points for being matched with $D$ (Table 1). Preference profiles are common knowledge.

$$
A \succ B \succ C \succ D
$$

Table 1: Student preferences

Universities have a priority for Type-1 students over Type-2 students (Table 2 ). These priorities over types are common knowledge. Students of the same type are ordered randomly. The order determines university priorities over students of the same type. Participants are told that priorities over students of the same type will be determined randomly, but the results of the lottery are not revealed to participants.

Students submit a complete rank-order list for universities. They are neither allowed to truncate their rank-order list nor to include the same university more than once in their rank-order list. While the large majority of matching experiments investigates repeated interactions, I conduct a one-shot matching experiment. The

17. For the instructions of the experiment, see Appendix A.5.

18. The main reason for this design choice is that the basic parameters of this design spur strategies of different complexity for different types under the BOS mechanism. This is a feature that I exploit in my treatment variations when targeting different types with different information about the strategic properties of the mechanism.

19. Type-1 students can be thought of as "top students", Type-2 students as "average students". While the experiment is framed as a school choice problem, the instructions do not refer to "top students" and "average students" in order to prevent a feeling of superiority or envy. 


$$
\begin{array}{ccc}
s_{1}, s_{2}, s_{3} & \succ & s_{4}, s_{5} \\
\text { Type } 1 & \text { Type } 2
\end{array}
$$

Table 2: University priorities

reason for this design choice is that many matching markets, such as those for university admissions, involve an important once-in-a-lifetime decision. Students are often unfamiliar with the procedure and may only learn about sensible application strategies from other people in their social network who experienced the procedure in the past (Ding and Schotter 2017, 2019). Without such intergenerational advice and without the possibility to engage in repeated interactions, however, students are unlikely to fully grasp the strategic properties of the assignment procedure or trust it.

Under the BOS mechanism, in equilibrium Type-2 students will adopt one strategy (skip-the-top), Type-1 students another (skip-the-middle). Type-2 students know that the two seats at $A$ will be assigned to two Type- 1 students. Therefore, they have an incentive to misreport their first preference and rank $B$ first rather than $A$. This strategy can be referred to as skip-the-top. Conversely, rational Type-1 students will anticipate that the seat at $B$ will already be blocked if they do not obtain a seat at $A$, their most preferred option. They will therefore insure themselves against the risk of foregoing a seat at $C$ and rank it second instead of $B$. This strategy can be referred to as skip-the-middle.

\subsection{Treatments}

Under each matching mechanism, I vary the degree of information about the mechanism in three treatments. In the baseline treatment, participants receive detailed information about procedural rules of the respective matching mechanism including some examples (Base). ${ }^{20}$ In the strategic information treatment, participants only receive information about the respective equilibrium strategies without an explanation of the procedural rules of the respective matching mechanism (Strat-

20. For the instructions of the experiment, see Appendix A.5. 
Info). The combined information treatment combines both treatments (Combined). Hence, participants receive both information about the procedural rules of the respective matching mechanism and strategic information. ${ }^{21}$

The GS StratInfo treatment mimicks the kind of procedural information provided by some public school districts in the US (see Section 2). Accordingly, participants receive specific information that strategizing is not beneficial: "Regardless of what other students do, you will never be better off by submitting a rank-order list that does not reflect your true preferences. This means: Your chances of being admitted to a preferred university (= yielding higher earnings) do not improve if you put a less preferred university (= yielding lower earnings) on a higher rank on the rank-order list. For example, neither Type- 1 students nor Type-2 students can improve their chances of being admitted to a preferred university by ranking university $\mathrm{A}$ as their second choice and university $\mathrm{B}$ as their first choice."

The BOS StratInfo treatment approximates the practice of the German clearinghouse in charge of university admissions (see Section 2). Accordingly, participants receive specific information about potentially beneficial strategies for each type: "Depending on what other students do, you might be better off by submitting a rank-order list that does not reflect your true preferences. This means: Your chances of being admitted to a preferred university (= yielding higher earnings) might improve if you put a less preferred university (= yielding lower earnings) on a higher rank on the rank-order list. Type- 2 students might be better off by manipulating their first choice, e.g. rank university B as their first choice. In that case, Type-1 students might be better off by manipulating their second choice, e.g. rank university $\mathrm{C}$ as their second choice. This can increase the chances for Type-1 students of being admitted at university $\mathrm{C}$ if no seat at university $\mathrm{B}$ is available any more."

21. While these treatment variations are related to the advice manipulations implemented by Guillen and Hakimov (2018), these authors (i) explore a different mechanism (TTC mechanism), (ii) do not investigate how procedural information affects preference manipulations on matching markets with different student types, and (iii) do not compare the impact of procedural information across different mechanisms. 


\subsection{Post-experimental tests}

After implementing the respective matching mechanism, I first elicited first-order beliefs about other participants' strategies. The belief elicitation task was announced after participants had made their decision under the matching mechanism so as not to trigger strategic considerations based on beliefs. In order to prevent hedging across tasks, the belief elicitation stage was not incentivized. Second, I elicited risk preferences using the measure proposed by Holt and Laury (2002). Third, I measured cognitive abilities and heuristics related to intuition using an incentivized version of the cognitive reflection test (Frederick 2005). The cognitive reflection test is designed to measure the ability to inhibit intuitive responses (System 1 thinking) when the correct response requires conscious reflection (System 2 thinking). Participants in previous studies have been shown to be familiar with the answers from the original version of the cognitive reflection test (Haigh 2016; Stieger and Reips 2016). In order to prevent a biased measure due to experience with the test, I used three questions from the original version of the test and three questions from a recent version. Each participant had one minute to answer each test question. Fourth, I measured fairness perceptions using survey questions developed in the literature on procedural fairness (Lind and Tyler 1988; Colquitt and Rodell 2015). The experiment ended with a demographics questionnaire to control for gender, age, subject studied, and experience with the German university admissions procedure for medical school.

\subsection{Procedure}

The experiment was programmed using the experimental software $z$-Tree (Fischbacher 2007) and the matchingMarkets package in R (Klein and Giegerich 2018). ${ }^{22}$ The experiment was conducted at the DecisionLab of the Max Planck Institute for Research on Collective Goods in 2018, with a total of 235 participants. Subjects were recruited via ORSEE (Greiner 2015) and participated in 13 sessions. Each session lasted approximately 60 minutes. Before the experiment, partici-

22. The code used for the experimental program is included in Appendix A.3. 
pants had to answer control questions correctly in order to begin with the actual experiment. At the end of the experiment, participants received the sum of their earnings, including a show-up fee of 5 Euros. Participants earned 14.57 Euros on average. In addition, I ran simulations to predict matchings and their stability using the matchingR (Tilly and Janetos 2018) and the matchingMarkets packages in R (Klein and Giegerich 2018). ${ }^{23}$

\subsection{Hypotheses}

Under the GS mechanism, a strategy profile is an equilibrium if and only if Type1 students rank $A$ first and $B$ second and Type-2 students rank $C$ among the acceptable offers (see Featherstone and Niederle 2016). ${ }^{24}$ Truth-telling is a weakly dominant strategy. Under the BOS mechanism, a strategy profile is an equilibrium if and only if Type- 1 students rank $A$ first and $C$ second, and Type- 2 students rank $B$ first (see Featherstone and Niederle 2016). It follows that students have an incentive to manipulate their preferences under the BOS mechanism.

Hypothesis 1. Truth-telling rates are higher under the GS mechanism than under the BOS mechanism.

The strategic information treatment is designed to increase the salience of the equilibrium strategy and dampen strategic considerations as compared to the baseline treatment and the combined information treatment. Under the GS mechanism, strategic information should spur applicants to adopt a truth-telling strategy. Under the BOS mechanism, Type-1 students should be more likely to skip the middle, while Type- 2 students should be more likely to skip the top when receiving strategic information. Combined information dampens the salience of the equilibrium strategy; it should trigger strategic considerations and off-equilibrium behavior.

Hypothesis 2. Students are more likely to adopt the equilibrium strategy in the strategic information treatment than in the combined information treatment and the baseline treatment.

23. The code used for the simulations is included in Appendix A.2.

24. Featherstone and Niederle (2016) characterize this equilibrium as Bayes-Nash equilibrium. 
In equilibrium, the GS mechanism will result in the unique stable matching, where two Type- 1 students (with the two highest ranks among Type- 1 students) are matched to $A$, one Type- 1 student is matched to $B$, one Type-2 student (with the highest rank among Type- 2 students) is matched to $C$, and one Type- 2 student is matched to $D$.

$$
\mu_{G S}=\left(\begin{array}{cccc}
A & B & C & D \\
s_{1}, s_{2} & s_{3} & s_{4} & s_{5}
\end{array}\right)
$$

Under the equilibrium matching of the BOS mechanism, the Type-1 student with the lowest rank among students of her type will be matched to $C$ or $D$. It follows that the resulting matching will not be stable: the respective Type-1 student would prefer to be matched to $B$, and the priority of Type- 1 students at $B$ will be systematically violated.

$$
\mu_{B O S}=\left(\begin{array}{cccc}
A & B & C & D \\
s_{1}, s_{2} & s_{4} & s_{3}\left(s_{5}\right) & s_{5}\left(s_{3}\right)
\end{array}\right)
$$

Hypothesis 3. Stability levels are higher under the GS mechanism than under the BOS mechanism, and higher in the strategic information treatment than in the combined information treatment and the baseline treatment.

In line with previous findings (Basteck and Mantovani 2018), cognitive abilities should be correlated with strategic abilities and facilitate individually optimal choices regardless of the procedural rules.

Hypothesis 4. Students with higher cognitive abilities are more likely to adopt the equilibrium strategy under both mechanisms.

The fairness of a public assignment procedure depends both on the outcome it generates and on the transparency of its procedural rules (see Section 3). Stability implies that no student prefers another school, while a student with a lower 
priority is matched to that school, which should increase perceived outcome fairness (Kamada and Kojima 2019). Strategy-proofness implies that the mechanism does not provide any advantage to sophisticated students, which should increase procedural fairness.

Hypothesis 5. Perceived fairness is higher under the GS mechanism than under the BOS mechanism.

\section{$5 \quad$ Results}

\subsection{Summary}

In my data analysis, I use both non-parametric tests and parametric regression models. All p-values are those of a Fisher's exact test if not otherwise reported. Table 3 presents the summary results for strategic behavior under the GS mechanism and the BOS mechanism. ${ }^{25}$ In line with Hypothesis 1, I find that truthtelling rates are significantly higher under the GS mechanism than under the BOS mechanism $(p<0.001)$. This results holds both for Type- 1 and Type- 2 students $(p<0.001)$. Conversely, skip-the-middle rates are significantly higher under the BOS mechanism than under the GS mechanism $(p=0.001)$. In line with Hypothesis 2 , this effect is driven by Type- 1 students. Type- 1 students are more likely to skip the middle under the BOS mechanism than under the GS mechanism $(p<0.001)$, while I do not find any difference for Type-2 students $(p=0.598)$. Skip-the-top rates are significantly higher under the BOS mechanism than under the GS mechanism $(p<0.001)$. In line with Hypothesis 2 , this effect is mainly driven by Type-2 students. Type- 2 students are more likely to skip the top under the BOS mechanism than under the GS mechanism $(p<0.001)$, but a similar yet marginally significant effect can be observed for Type- 1 students $(p=0.081)$. These results corroborate the theoretical prediction that the GS mechanism will yield higher truth-telling rates than the BOS mechanism and that students will adopt type-specific strategies under the BOS mechanism.

25. Truth: ABCD; Skip-the-middle: ACBD; Skip-the-top: BCAD or BACD. p-values according to a Fisher's exact test. 
Table 3: Strategic behavior across mechanisms

\begin{tabular}{lccc}
\hline & GS & BOS & p-value \\
\hline Truth & $73.60 \%$ & $36.36 \%$ & $<0.001$ \\
Skip-the-middle & $1.60 \%$ & $13.64 \%$ & 0.001 \\
Skip-the-top & $14.40 \%$ & $38.18 \%$ & $<0.001$ \\
CABD & $4.00 \%$ & $1.82 \%$ & 0.453 \\
CBAD & $4.80 \%$ & $6.36 \%$ & 0.776 \\
\hline$N$ & 125 & 110 & \\
\hline
\end{tabular}

Result 1. Truth-telling rates are higher under the GS mechanism than under the BOS mechanism when aggregating over all information environments.

\subsection{Treatment effects on truth-telling strategies}

Table 4 shows a more nuanced picture of treatment effects on truth-telling. These nuances are visualized in Figure 1.

Table 4: Strategic behavior in all treatments

\begin{tabular}{lcccccccc}
\hline & \multicolumn{4}{c}{ GS } & & \multicolumn{3}{c}{ BOS } \\
\cline { 2 - 3 } \cline { 7 - 8 } & Base & StratInfo & Combined & & Base & StratInfo & Combined \\
\hline Truth & $53.33 \%$ & $85.00 \%$ & $85.00 \%$ & & $51.43 \%$ & $32.50 \%$ & $25.71 \%$ \\
Skip-the-middle & $2.22 \%$ & $0.00 \%$ & $2.50 \%$ & & $8.57 \%$ & $17.50 \%$ & $14.29 \%$ \\
Skip-the-top & $26.67 \%$ & $7.50 \%$ & $7.50 \%$ & & $34.29 \%$ & $37.50 \%$ & $42.86 \%$ \\
\hline$N$ & 45 & 40 & 40 & & 35 & 40 & 35 \\
\hline
\end{tabular}

First, I analyze the difference in truth-telling rates across both baseline treatments. Contrary to all theoretical predictions, truth-telling rates do not significantly differ across the baseline GS and the baseline BOS mechanism $(p=1.000)$. Running a test for the two student types separately, I find a difference neither for Type- 1 students $(p=0.750)$ nor for Type-2 students $(p=0.426)$. A multinomial logistic regression corroborates this result (Table 5). This suggests that the GS mechanism and the BOS mechanism will not yield different truth-telling rates on 
average if students receive information about the mechanism only. One potential explanation may be that students fail to fully grasp the strategic implications of the mechanism when only its rules are explained. A comparison with the equilibrium prediction elucidates the intensity of this behavioral effect. Truth-telling rates under the baseline GS mechanism $(53.33 \%)$ are not even close to the equilibrium prediction $(100 \%)$. This prompts the conclusion that students strategize excessively under the GS mechanism when they do not receive information about its strategic properties.

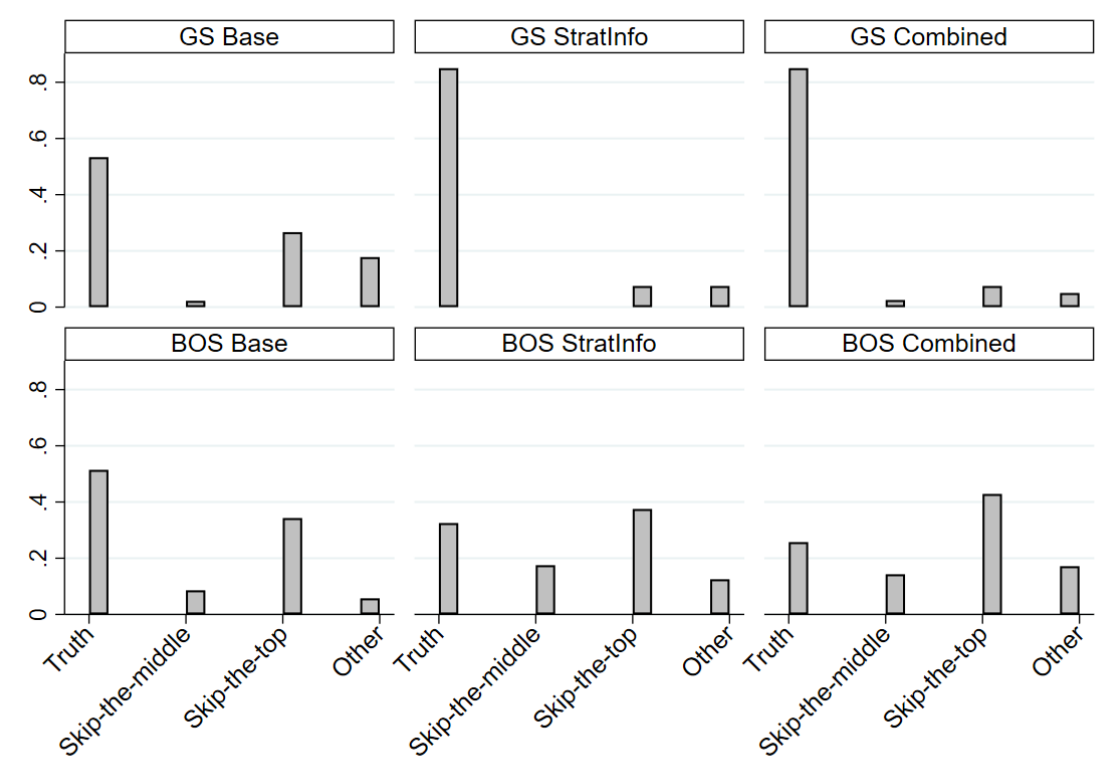

Figure 1: Distribution of strategies in all treatments

Second, I analyze the impact of procedural information on truth-telling within each mechanism. In line with Hypothesis 2, both the strategic information and the combined information treatments lead to a strong and significant increase of truth-telling rates as compared to the baseline under the GS mechanism ( $p=$ 0.002 and $p=0.002) .{ }^{26}$ Conversely, the strategic information and the combined

26. Running a test for the two student types separately, I obtain the same results. Comparison between GS Base and GS StratInfo: both Type-1 students and Type-2 students are more likely to adopt the truth-telling strategy under GS StratInfo $(p=0.005$ and $p=0.082)$. Comparison 
Table 5: Treatment effects on strategies

\begin{tabular}{lcccc}
\hline & Truth & Skip-the-middle & Skip-the-top & Other \\
\hline Ref. cat.: GS Base & & & & \\
GS StratInfo & $\begin{array}{c}0.317^{* * *} \\
(0.093)\end{array}$ & $\begin{array}{c}-0.022^{* * *} \\
(0.022)\end{array}$ & $-0.192^{* *}$ & -0.103 \\
& & & $(0.078)$ & $(0.071)$ \\
GS Combined & $0.317^{* * *}$ & 0.003 & $-0.192^{* *}$ & $-0.128^{*}$ \\
& $(0.093)$ & $(0.033)$ & $(0.078)$ & $(0.067)$ \\
BOS Base & -0.019 & 0.064 & 0.076 & $-0.121^{*}$ \\
& $(0.113)$ & $(0.052)$ & $(0.104)$ & $(0.069)$ \\
BOS StratInfo & $-0.208^{* *}$ & $0.153^{* *}$ & 0.108 & -0.053 \\
& $(0.105)$ & $(0.064)$ & $(0.101)$ & $(0.077)$ \\
BOS Combined & $-0.276^{* * *}$ & $0.121^{*}$ & 0.162 & -0.006 \\
& $(0.105)$ & $(0.063)$ & $(0.107)$ & $(0.085)$ \\
\hline
\end{tabular}

${ }^{* * *} p<0.01 ;{ }^{* *} p<0.05 ;{ }^{*} p<0.1$

Multinomial logit regression. Standard errors in parentheses. Treatment coefficients are reported as average marginal treatment effects. All columns report estimates of one and the same multinomial logit regression. Each cell can be interpreted as the difference in the probability of adopting one of the reported strategies (categorical DV: Truth, Skip-themiddle, Skip-the-top, Other) between the respective treatment and GS Base (reference category). 
information treatments trigger a drop in truth-telling rates as compared to the baseline under the BOS mechanism $(p=0.107$ and $p=0.049) .{ }^{27}$ This negative effect is in line with the prediction that truth-telling rates should further decline under the BOS mechanism if students receive information about a potentially beneficial manipulation of preferences.

Result 2. Strategic information and combined information lead to a strong increase of truth-telling under the GS mechanism, and to a strong decrease of truth-telling under the BOS mechanism.

\subsection{Treatment effects on dropping strategies}

The experiment was also designed to test whether information about the respective equilibrium strategies (dropping strategies) facilitates individually beneficial manipulations of rank-order lists under the BOS mechanism. Accordingly, the data analysis in this subsection only considers observations from the BOS mechanism. Aggregating over all information environments under the BOS mechanism, only $13.64 \%$ of students skip the middle, while $38.18 \%$ of students adopt the skip-the-top strategy (Table 3). Skip-the-top rates are relatively close to the equilibrium (40\%), but skip-the-middle rates are far below the equilibrium prediction $(60 \%)$. Overall, this suggests that regardless of the specific information about the assignment procedure students fail to use individually optimal strategies under the BOS mechanism. This is corroborated by the fact that $36.36 \%$ of students opt for the truth-telling strategy even though a preference manipulation would make them better off.

In line with Hypothesis 2, Type-1 students adopt the skip-the-middle strategy between GS Base and GS Combined: both Type-1 students and Type-2 students are more likely to adopt the truth-telling strategy under GS Combined ( $p=0.026$ and $p=0.037)$.

27. Running a test for the two student types separately, I find that this effect is mainly driven by Type-1 students. Comparison between BOS Base and BOS StratInfo: Type-1 students seem to be less likely to adopt the truth-telling strategy under BOS StratInfo ( $p=0.123)$, while I do not find a difference for Type- 2 students $(p=0.586)$. Comparison between BOS Base and BOS Combined: Type-1 students are less likely to adopt the truth-telling strategy under BOS Combined ( $p=0.058)$, while I do not find a difference for Type-2 students $(p=0.481)$. 
more frequently $(19.70 \%)$ than Type-2 students $(4.55 \%, p=0.025)$. Conversely, Type-2 students skip the top more frequently $(68.18 \%)$ than Type-1 students $(18.18 \%, p<0.001)$. This suggest that students have a sense of which strategy to adopt in light of the priorities that universities set for their individual type and the strategic incentives set by the BOS mechanism. The impact of procedural information on both types becomes clear in an analysis that distinguishes between Type- 1 and Type- 2 students across all treatments.

On the one hand, only $14.29 \%$ of Type-1 students skip the middle under the baseline BOS mechanism. Skip-the-middle rates increase to $25.00 \%$ in the strategic information treatment and to $19.05 \%$ in the combined information treatment. Using a Fisher's exact test, however, this tendency towards the equilibrium strategy is not significant $(p=0.469$ and $p=1.000)$. Regardless of the specific information environment, Type-1 students fail to skip the middle sufficiently often so as to improve their prospects of obtaining the best possible matching.

On the other hand, $71.43 \%$ of Type- 2 students skip the top under the baseline BOS mechanism. Skip-the-top rates drop to $56.25 \%$ in the strategic information treatment, and increase to $78.57 \%$ in the combined information treatment. Yet none of these changes is significant when using a Fisher's exact test $(p=0.466$ and $p=1.000$ ). This suggests that Type-2 students are also subject to bounded rationality and fail to adopt the skip the top strategy sufficiently often.

A multinomial logistic regression with the baseline GS mechanism as the reference category yields some evidence in support of Hypothesis 2 (Table 6). Type-1 students are more likely to skip the middle when receiving strategic information or combined information under the BOS mechanism. Conversely, Type-2 students are more likely to skip the top when receiving combined information under the BOS mechanism, whereas merely providing strategic information does not seem to facilitate the adoption of the skip-the-top strategy.

However, a multinomial logistic regression with the baseline BOS mechanism as the reference category shows that the treatments under the BOS mechanism have a negative effect on truth-telling but no positive effect on any of the dropping strategies (Appendix A.4.1.). One potential reason for not observing a treatment 
Table 6: Treatment effects on strategies

\begin{tabular}{|c|c|c|c|c|}
\hline Strategy & Truth & Skip-the-middle & Skip-the-top & Other \\
\hline \multicolumn{5}{|c|}{ Ref. cat.: GS Base } \\
\hline \multicolumn{5}{|c|}{ GS StratInfo } \\
\hline \multirow[t]{2}{*}{ Type 1} & $0.296^{* * *}$ & -0.0370 & $-0.222^{* * *}$ & -0.037 \\
\hline & $(0.088)$ & $(0.036)$ & $(0.080)$ & $(0.036)$ \\
\hline \multirow[t]{2}{*}{ Type 2} & $0.347^{* *}$ & $<0.001$ & -0.146 & -0.201 \\
\hline & $(0.161)$ & $(<0.001)$ & $(0.148)$ & $(0.151)$ \\
\hline \multicolumn{5}{|c|}{ GS Combined } \\
\hline \multirow[t]{2}{*}{ Type 1} & $0.255^{* * *}$ & -0.037 & $-0.222^{* * *}$ & 0.005 \\
\hline & $(0.097)$ & $(0.036)$ & $(0.080)$ & $(0.055)$ \\
\hline \multirow[t]{2}{*}{ Type 2} & $0.410^{* * *}$ & 0.063 & -0.146 & $-0.326^{* *}$ \\
\hline & $(0.157)$ & $(0.061)$ & $(0.148)$ & $(0.130)$ \\
\hline \multicolumn{5}{|l|}{ BOS Base } \\
\hline \multirow[t]{2}{*}{ Type 1} & 0.058 & 0.106 & -0.127 & -0.037 \\
\hline & $(0.128)$ & $(0.085)$ & $(0.102)$ & $(0.036)$ \\
\hline \multirow[t]{2}{*}{ Type 2} & -0.135 & $<0.001$ & $0.381^{* *}$ & $-0.246^{*}$ \\
\hline & $(0.1410)$ & $(<0.001)$ & $(0.164)$ & $(0.148)$ \\
\hline \multicolumn{5}{|c|}{ BOS StratInfo } \\
\hline \multirow[t]{2}{*}{ Type 1} & -0.204 & $0.213^{* *}$ & 0.028 & -0.037 \\
\hline & $(0.135)$ & $(0.096)$ & $(0.119)$ & $(0.036)$ \\
\hline \multirow[t]{2}{*}{ Type 2} & $-0.215^{*}$ & 0.062 & 0.229 & -0.076 \\
\hline & $(0.122)$ & $(0.061)$ & $(0.167)$ & $(0.163)$ \\
\hline \multicolumn{5}{|c|}{ BOS Combined } \\
\hline \multirow[t]{2}{*}{ Type 1} & $-0.275^{* *}$ & $0.153^{*}$ & -0.032 & $0.153^{*}$ \\
\hline & (0.139) & $(0.093)$ & $(0.117)$ & $(0.093)$ \\
\hline \multirow[t]{2}{*}{ Type 2} & $-0.278^{* * *}$ & 0.071 & $0.452^{* * *}$ & $-0.246^{*}$ \\
\hline & $(0.106)$ & $(0.069)$ & $(0.156)$ & $(0.148)$ \\
\hline
\end{tabular}

${ }^{* * *} p<0.01 ;{ }^{* *} p<0.05 ;{ }^{*} p<0.1$

Multinomial logit regression with interaction between treatment and type. Standard errors in parentheses. Treatment coefficients are reported as average marginal treatment effects. All columns report estimates of one and the same multinomial logit regression. Each cell can be interpreted as the difference in the probability of adopting one of the reported strategies (categorical DV: Truth, Skip-the-middle, Skip-the-top, Other) between the respective treatment and GS Base (reference category) for Type-1 students (top panel) and Type-2 students (bottom panel). 
effect on skip-the-top rates is that a relatively high fraction of Type- 2 students adopt a skip-the-top strategy under the baseline BOS mechanism (71.43\%). In sum, this suggests that it is rather difficult to nudge students to adopt any dropping strategy, be it a simple one (skip-the-top) or a complex one (skip-the-middle). On the one hand, this indicates that information about the strategic properties of the mechanism may not be necessary to push students towards a simple dropping strategy. On the other hand, these results prompt the conclusion that even simple explanations of complex strategies may be too difficult to fathom.

The relatively high skip-the-top rates under the baseline BOS mechanism can be explained by risk aversion. A multinomial logistic regression shows that risk averse students are more likely to skip the top (Appendix A.4.2.). These students may be afraid of foregoing a potential seat at university B and thus downrank university A on their rank-order preference list.

Overall, providing procedural information about how to strategize does not seem to facilitate the adoption of equilibrium strategies under the BOS mechanism. Even when provided with strategic and combined information, students do not entirely converge towards the equilibrium. On average, $22 \%$ of Type- 1 students skip the middle (equilibrium: $100 \%$ ), while $67 \%$ of Type-2 students skip the top (equilibrium: $100 \%$ ) in the strategic information treatment and the combined information treatment.

Result 3. Strategic information and combined information do not seem to facilitate the adoption of equilibrium strategies under the BOS mechanism.

\subsection{Stability}

A matching is stable if no student can form a blocking pair with a university. A blocking pair exists if a student prefers to be admitted at a university with a seat that has been assigned to a student with a lower priority. Under the studentproposing GS mechanism, a student-optimal stable matching is achieved when all students reveal their preferences truthfully. Table 7 reports the fraction of stable matchings across all treatments and corroborates this hypothesis.

Overall, the results are in line with Hypothesis 3 and show that the GS mech- 
Table 7: Stable matchings

\begin{tabular}{ccccccc}
\hline \multicolumn{3}{c}{ GS } & & \multicolumn{3}{c}{ BOS } \\
\cline { 2 - 3 } \cline { 5 - 7 } Base & StratInfo & Combined & & Base & StratInfo & Combined \\
\hline $33.33 \%$ & $100 \%$ & $87.50 \%$ & & $0 \%$ & $12.50 \%$ & $0 \%$ \\
\hline
\end{tabular}

anism yields a higher fraction of stable matchings than the BOS mechanism $(p<0.001)$. While I do not observe strong treatment differences under the BOS mechanism, I find stark treatment differences under the GS mechanism. Specifically, the fraction of stable matchings is extremely low under the GS mechanism in the baseline treatment $(33.33 \%)$, while increasing to $100 \%$ in the strategic information treatment $(p<0.001)$ and $87.50 \%$ in the combined information treatment $(p<0.001)$. A logistic regression confirms this result (Appendix A.4.3.).

This result can again be explained by the high fraction of students who manipulate their preferences under the GS mechanism in the baseline treatment. The results also show that full transparency about both the mechanism and its strategic properties (as implemented in the combined information treatment) may not be the best approach to achieve stability. In fact, the results point at a potential trade-off between transparency and stability.

Result 4. Strategic and combined information increase the stability of matchings under the GS mechanism, while leaving it unaffected under the BOS mechanism.

\subsection{Cognitive abilities}

In line with Hypothesis 4, cognitive reflection abilities partly explain the strategies adopted under both mechanisms. A multinomial logistic regression provides evidence in support of this result (Appendix A.4.4.). Under the GS mechanism, higher cognitive abilities do not seem to have a positive effect on truth-telling. However, students with higher cognitive abilities are more likely to refrain from a skip-the-top strategy when receiving strategic information, whereas students with lower cognitive abilities are more likely to refrain from a skip-the-top strategy when receiving combined information. Under the BOS mechanism, higher cogni- 
tive abilities lead to an increase in skip-the-middle rates with strategic information, whereas lower cognitive abilities lead to an increase in skip-the-middle rates with combined information.

On the one hand, this result suggests that students with higher cognitive abilities are willing to trust strategic information even when the actual procedure is unknown, while students with lower cognitive abilities seem to have a preference for additional information about the assignment procedure. On the other hand, this result stands in contrast to previous findings showing that students with lower cognitive abilities fail to strategize optimally (Basteck and Mantovani 2018).

One potential reason for only observing an effect on the skip-the-middle strategy is that this strategy is relatively difficult. Type- 1 students need to anticipate strategic behavior by Type-2 students and react with a counter-strategy, whereas Type-2 students only need to anticipate the outcome of the procedure conditional on Type-1 students ranking $A$ on top of their rank-order list. Type-2 students can thus adopt a sensible strategy based on first-order beliefs about truth-telling among Type-1 students, while Type-1 students have to form first-order beliefs about preference manipulations among Type-2 students.

Result 5. Cognitive reflection abilities facilitate the adoption of equilibrium strategies both under the GS mechanism and under the BOS mechanism.

\subsection{Fairness}

Table 8 presents the results of an ordered probit regression. The dependent variables stem from a Likert scale survey widely used in procedural fairness studies (Lind and Tyler 1988; Colquitt and Rodell 2015). ${ }^{28}$ On the one hand, I find that the outcomes generated under the BOS mechanism in both the strategic information and the combined information treatments are perceived as fairer than those generated under the GS mechanism. On the other hand, the results show that fairness assessments of the procedure remain unaffected by the treatments in

28. The questions used for the survey are included in Appendix A.5. 
comparison to the baseline GS mechanism. ${ }^{29}$ At the same time, the information provided in the strategic information and the combined information treatments under the BOS mechanism is perceived as less trustworthy. Finally, the results show that providing strategic information under the GS mechanism has a positive impact on the comprehensibility of the procedure.

These results do not provide straightforward evidence in support of Hypothesis 5. Rather, they indicate that strategy-proofness - as a criterion of procedural fairness - and stability - as a criterion for outcome fairness - do not square with general sentiments about fair assignment procedures (for a theoretical foundation of these fairness concepts, see Section 3). In fact, the results are somewhat opposed to the idea that creating a level playing field through strategy-proofness and eliminating justified envy are indispensable ingredients of fair assignment procedures, an idea that features prominently in matching theory (see Pathak and Sönmez 2008; Kamada and Kojima 2019). Not only do these results point at an inherent tension between perceived outcome fairness on the one hand and strategy-proofness on the other hand. They also suggest that strategy-proofness and transparency of assignment procedures embody different - and at times conflicting - fairness notions.

While market designers tend to derive their fairness concepts from strategyproofness, legal scholars tend to stress the importance of procedural transparency. By contrast, the results presented here indicate that neither strategy-proofness nor transparency entirely translate into any concept of procedural or outcome fairness. On the one hand, the results suggest that in order to fully deploy the virtues of strategy-proofness, it is crucial to provide salient information about the strategic properties of the mechanism. As the treatment comparisons under the GS mechanism show, sound explanations of the procedural rules alone are not sufficient to

29. The GS mechanism implies that students incur the risk of losing a seat they have been temporarily assigned if other students with a higher priority apply at the university in later steps of the algorithm. Students with reference-dependent preferences could perceive this as a loss, which could negatively affect their fairness assessment of the GS mechanism. However, this does not explain my results, as students do not know the exact procedure in the strategic information treatment and are therefore unable to form expectations based on temporary assignments. 
prevent attempts to game the assignment procedure, but they do not negatively affect truth-telling if presented in combination with salient strategic information. On the other hand, even when the strategic properties are transparent and salient, neither strategy-proofness nor the transparency of the specific procedural rules seem to be a driving force of the perceived fairness of the procedure. One reason may be that students perceive the GS mechanism as being "mechanic" and imposing strict preferences (Hitzig, forthcoming), while they may feel that the outcome generated under the BOS mechanism can be improved through behavior perceived as smart. The feeling of being able to exercise process control or "voice" (Thibaut and Walker 1978) and not simply being a cog in the mechanism designer's wheel might explain why fairness assessments are higher under the BOS mechanism.

Result 6 . When students are provided with strategic and combined information, outcomes are perceived as fairer under the BOS mechanism than under the GS mechanism. Procedural fairness assessments do not seem to differ across mechanisms.

\section{Conclusion}

In this article, I have investigated the impact of different types of procedural information on stability, strategic behavior and perceived fairness under the GS mechanism and the BOS mechanism. Understanding the impact of procedural information is crucial - for matching theorists who tend to discount potential behavioral effects, for market designers who need to design matching mechanisms in light of bounded rationality, and for lawyers who need to evaluate these mechanisms. To explore the impact of procedural information, I compare three different information environments in an experiment: information about the rules of the assignment procedure, information about its strategic properties (i.e. equilibrium strategies), and a combination of both (i.e. full transparency).

First, I find no difference in truth-telling rates (approximately $50 \%$ ) between the GS mechanism and the BOS mechanism when merely informing applicants about the rules of the respective mechanism. Second, information about the 
Table 8: Treatment effects on perceived fairness

\begin{tabular}{|c|c|c|c|c|}
\hline & Outcome fairness & Procedural fairness & Comprehension & Trustworthiness \\
\hline \multicolumn{5}{|c|}{ Ref. cat.: GS Base } \\
\hline \multirow[t]{2}{*}{ GS StratInfo } & 0.255 & 0.051 & $0.529^{* *}$ & -0.394 \\
\hline & $(0.227)$ & $(0.231)$ & $(0.242)$ & $(0.245)$ \\
\hline \multirow[t]{2}{*}{ GS Combined } & 0.127 & -0.012 & 0.202 & -0.269 \\
\hline & $(0.228)$ & $(0.231)$ & $(0.236)$ & $(0.248)$ \\
\hline \multirow[t]{2}{*}{ BOS Base } & 0.104 & 0.182 & 0.310 & -0.270 \\
\hline & $(0.236)$ & $(0.238)$ & $(0.248)$ & $(0.256)$ \\
\hline \multirow[t]{2}{*}{ BOS StratInfo } & $0.453^{* *}$ & 0.094 & 0.049 & $-0.606^{* *}$ \\
\hline & $(0.226)$ & $(0.230)$ & $(0.235)$ & $(0.243)$ \\
\hline \multirow[t]{2}{*}{ BOS Combined } & $0.605^{* * *}$ & 0.210 & 0.170 & $-0.596^{* *}$ \\
\hline & $(0.235)$ & $(0.238)$ & $(0.242)$ & $(0.250)$ \\
\hline$N$ & 235 & 235 & 235 & 235 \\
\hline \multicolumn{5}{|c|}{${ }^{* * *} p<0.01 ;{ }^{* *} p<0.05 ;{ }^{*} p<0.1$} \\
\hline $\begin{array}{l}\text { Ordered probit } \\
\text { ordered probit } \mathrm{r} \\
\text { (very fair). Pro } \\
\text { Comprehension } \\
\text { procedure was co } \\
\text { variable describi } \\
\text { ranging from } 1 \text { ( }\end{array}$ & $\begin{array}{l}\text { ssion. Standard erro } \\
\text { sion. Outcome fairn } \\
\text { al fairness is an ord } \\
\text { ordinal variable descl } \\
\text { hensible ranging from } \\
\text { e extent to which th } \\
t \text { all) to } 7 \text { (completel }\end{array}$ & $\begin{array}{l}\text { rs in parentheses. Eac } \\
\text { ess is an ordinal varial } \\
\text { inal variable ranging } \mathrm{f} \\
\text { ribing the extent to wh } \\
1 \text { (not at all) to } 7 \text { (com } \\
\text { e explanation of the as } \\
\text { y). }\end{array}$ & $\begin{array}{l}\text { ch column corresp } \\
\text { ole ranging from } 1 \\
\text { rom } 1 \text { (very unfai } \\
\text { ich the explanatio } \\
\text { pletely). Trustwor } \\
\text { ssignment procedu }\end{array}$ & $\begin{array}{l}\text { onds to a different } \\
\text { (very unfair) to } 7 \\
\text { ir) to } 7 \text { (very fair). } \\
n \text { of the assignment } \\
\text { thiness is an ordinal } \\
\text { rre was trustworthy }\end{array}$ \\
\hline
\end{tabular}


strategic properties of the mechanism and full transparency significantly increase truth-telling rates and the fraction of stable matchings under the GS mechanism. Under the BOS mechanism, however, information about the strategic properties of the mechanism and full transparency only reduce truth-telling, without a positive effect on the adoption of equilibrium strategies. Third, I find that cognitive reflection abilities only facilitate the adoption of complex dropping strategies spurred by the BOS mechanism, such as skip-the-middle. Finally, the GS mechanism does not seem to increase fairness perceptions. Contrary to prevailing assumptions in matching theory, perceived outcome fairness is higher under the BOS mechanism. This indicates that eliminating the incentives to game the system and dampening justified envy does not necessarily square with actual fairness perceptions.

These results have potentially important implications for the law and the policies applied to matching markets. While the introduction of strategy-proof school choice procedures is an important step towards a level playing field, it is unlikely to mitigate the risk of discrimination between sophisticated and non-sophisticated applicants without additional transparency policies. Rather, parents and students are likely to need specific procedural information about the strategy-proofness of the procedure lest unstable matchings be achieved. Public school districts in New York City and other cities around the world may be able to substantively improve their assignment procedures by urging applicants not to strategize and by increasing the salience of corresponding information about the assignment procedure. And courts may want to apply stricter scrutiny when assessing the compatibility of assignment procedures with equal protection rights.

On a normative view, the adoption of the GS mechanism can be considered as being close to the first-best solution if applicants receive strategic information. Without strategic information, the GS mechanism and the BOS mechanism might be equivalent second-best solutions. In addition to these transparency issues, market designers should also consider the possibility of a potential trade-off between strategy-proofness and actual fairness sentiments. A mechanism that incentivizes truthful preference revelation may level the playing field between sophisticated and non-sophisticated applicants, but it might infringe on applicants' perceived 
ability of exercising process control or "voice" and on their fairness perceptions. This illustrates that the design of safe, transparent and fair school choice procedures requires much more than just a strategy-proof matching mechanism. It is up to market designers and legal scholars to identify the relevant constraints that matching markets are subject to in practice. This is one of the core challenges of the emerging field of law and market design. 


\section{References}

Abdulkadiroğlu, Atila. 2013. "The Handbook of Market Design." Chap. School Choice, edited by Alvin E. Roth Nir Vulkan and Zvika Neeman, 138-169. Oxford University Press, Oxford/New York.

Abdulkadiroğlu, Atila, Yeon-Koo Che, Parag A. Pathak, Alvin E. Roth, and Olivier Tercieux. 2017. "Minimizing Justified Envy in School Choice: The Design of New Orleans' OneApp." Working Paper.

Abdulkadiroğlu, Atila, Parag A. Pathak, and Alvin E. Roth. 2005. "The New York City High School Match." American Economic Review 95 (2): 364-367.

Abdulkadiroğlu, Atila, Parag A. Pathak, Alvin E. Roth, and Tayfun Sönmez. 2005. "The Boston Public School Match." American Economic Review 95 (2): 368371.

Abdulkadiroğlu, Atila, and Tayfun Sönmez. 2003. "School Choice: A Mechanism Design Approach." American Economic Review 93 (3): 729-747.

Balinski, Michel, and Tayfun Sönmez. 1999. "A Tale of Two Mechanisms: Student Placement." Journal of Economic Theory 84:73-94.

Basteck, Christian, and Marco Mantovani. 2018. "Cognitive ability and games of school choice." Games and Economic Behavior 109:156-183.

Braun, Sebastian, Nadja Dwenger, and Dorothea Kübler. 2010. "Telling the Truth May Not Pay Off: An Empirical Study of Centralized University Admissions in Germany." The B.E. Journal of Economic Analysis $\&$ Policy 10 (1): 1-35.

Braun, Sebastian, Nadja Dwenger, Dorothea Kübler, and Alexander Westkamp. 2014. "Implementing quotas in university admissions: An experimental analysis." Games and Economic Behavior 85:232-251. 
Calsamiglia, Caterina, Guillaume Haeringer, and Flip Klijn. 2010. "Constrained School Choice: An Experimental Study." American Economic Review 100 (4): 1860-1874.

Chen, Yan, Yingzhi Liang, and Tayfun Sönmez. 2016. "School choice under complete information: An experimental study." Journal of Mechanism and Institution Design 1 (1): 45-82.

Chen, Yan, and Tayfun Sönmez. 2006. "School choice: an experimental study." Journal of Economic Theory 127 (1): 202-231.

Colquitt, Jason A., and Jessica B. Rodell. 2015. "The Oxford Handbook of Justice in the Workplace." Chap. Measuring Justice and Fairness, edited by Russell S. Cropanzano and Maureen L. Ambrose, 187-202. Oxford University Press, Oxford/New York.

Delacrétaz, David, Scott D. Kominers, and Alexander Teytelboym. 2016. "Refugee Resettlement." Working Paper.

Ding, Tingting, and Andrew Schotter. 2017. "Matching and chatting: An experimental study of the impact of network communication on school-matching mechanisms." Games and Economic Behavior 103:94-115.

—. 2019. "Learning and Mechanism Design: An Experimental Test of School Matching Mechanisms With Intergenerational Advice." Economic Journal 129.

Dubins, Lester E., and David A. Freedman. 1981. "Machiavelli and the GaleShapley algorithm." The American Mathematical Monthly 88 (7): 485-494.

Dworkin, Ronald. 1981. "What is equality? Part 2: Equality of resources." Philosophy and Public Affairs 10 (4): 283-345.

Echenique, Frederico, Alistair J. Wilson, and Leeat Yariv. 2016. "Clearinghouses for two-sided matching: An experimental study." Quantitative Economics 7:449482.

Ehlers, Lars, and Thayer Morrill. 2018. "(Il)legal Assignments in School Choice." Working Paper. 
Elster, Jon. 1992. Local Justice: How Institutions Allocate Scarce Goods and Necessary Burdens. Russell Sage Foundation, New York, NY.

Ergin, Haluk, and Tayfun Sönmez. 2006. "Games of school choice under the Boston mechanism." Journal of Public Economics 90 (1-2): 215-237.

Featherstone, Clayton R., and Eric Mayefsky. 2015. "Why Do Some Clearinghouses Yield Stable Outcomes? Experimental Evidence on Out-of-Equilibrium TruthTelling." Working Paper.

Featherstone, Clayton R., and Muriel Niederle. 2016. "Boston versus deferred acceptance in an interim setting: An experimental investigation." Games and Economic Behavior 100:353-375.

Fischbacher, Urs. 2007. "z-Tree: Zurich toolbox for ready-made economic experiments." Experimental Economics 10:171-178.

Frederick, Shane. 2005. "Cognitive reflection and decision making." Journal of Economic Perspectives 19 (4): 25-42.

Friedman, Milton. 1962. Capitalism and Freedom. University of Chicago Press, Chicago/London.

Gale, David, and Lloyd S. Shapley. 1962. "College admissions and the stability of marriage." The American Mathematical Monthly 69 (1): 9-15.

Garnett, Nicole S. 2017. "Sector Agnosticism and the Coming Transformation of Education Law." Vanderbilt Law Review 70 (1): 1-66.

Greiner, Ben. 2015. "Subject pool recruitment procedures: organizing experiments with ORSEE." Journal of the Economic Science Association 1 (1): 114-125.

Guillen, Pablo, and Rustamdjan Hakimov. 2017. "Not quite the best response: truth-telling, strategy-proof matching, and the manipulation of others." Experimental Economics 20 (3): 670-686.

2018. "The Effectiveness of top-down advice in strategy-proof mechanisms: A field experiment." European Economic Review 101:505-511. 
Guillen, Pablo, and Alexander Hing. 2014. "Lying through their teeth: Third party advice and truth telling in a strategy proof mechanism." European Economic Review 70:178-185.

Haeringer, Guillaume, and Flip Klijn. 2009. "Constrained school choice." Journal of Economic Theory 144 (5): 1921-1947.

Haigh, Matthew. 2016. "Has the Standard Cognitive Reflection Test Become a Victim of Its Own Success?" Advances in Cognitive Psychology 12 (3): 145149.

Hitzig, Zoë. Forthcoming. "Bridging the 'Normative Gap': Mechanism Design and Social Justice." Economics\&Philosophy.

Holt, Charles A., and Susan K. Laury. 2002. "Risk Aversion and Incentive Effects." American Economic Review 92:1644-1655.

Kamada, Yuichiro, and Fuhito Kojima. 2019. "Fair Matching Under Constraints: Theory and Applications." Working Paper.

Klein, Thilo, and Sven Giegerich. 2018. "Package 'matchingMarkets'." Working Paper.

Klijn, Flip, Joana Pais, and Marc Vorsatz. 2013. "Preference intensities and risk aversion in school choice: A laboratory experiment." Experimental Economics $16(1): 1-22$.

—. 2019. "Static versus dynamic deferred acceptance in school choice: Theory and experiment." Games and Economic Behavior 113:147-163.

Lind, E. Allan, and Tom R. Tyler. 1988. The Social Psychology of Procedural Justice. Springer Science \& Business Media, New York/London.

Mead, Julie F., and Maria M. Lewis. 2016. "The Implications of the Use of Parental Choice as a Legal "Circuit Breaker"." American Educational Research Journal $53(1): 100-131$. 
Milgrom, Paul R., and Steven Tadelis. 2019. "The Economics of Artificial Intelligence." Chap. How Artificial Intelligence and Machine Learning Can Impact Market Design, edited by Joshua Ajay Agrawal Gans and Avi Goldfarb, 567585. University of Chicago Press, Chicago/London.

Minow, Martha. 2010. In Brown's Wake: Legacies of America's Educational Landmark. Oxford University Press, Oxford/New York.

- 2011. "Confronting the Seduction of Choice: Law, Education, and American Pluralism." Yale Law Journal 120:814-848.

Pais, Joana, and Ágnes Pintér. 2008. "School choice and information: An experimental study on matching mechanisms." Games and Economic Behavior 64 (1): 303-328.

Pais, Joana, Ágnes Pintér, and Róbert F. Veszteg. 2011. "College Admissions and the Role of Information: An Experimental Study." International Economic Review 52:713-737.

Pathak, Parag A. 2017. "What Really Matters in Designing School Choice Mechanisms." In Advances in Economics and Econometrics: Eleventh World Congress, edited by Bo Honoré, Ariel Pakes, Monika Piazzesi, and Larry Samuelson, 1:176-214. Econometric Society Monographs. Cambridge University Press, Cambridge.

Pathak, Parag A., and Tayfun Sönmez. 2008. "Leveling the Playing Field: Sincere and Sophisticated Players in the Boston Mechanism." American Economic Review 98 (4): 1636-1652.

- 2013. "School admissions reform in Chicago and England: Comparing mechanisms by their vulnerability to manipulation." American Economic Review 103 (1): 80-106.

Posner, Eric A. Posner, and E. Glen Weyl. 2018. Radical Markets: Uprooting Capitalism and Democracy for a Just Society. Princeton University Press, Princeton, N.J. 
Rauch, Daniel E. 2015. "School Choice Architecture." Yale Law $\&$ Policy Review 34:187-198.

Rees-Jones, Alex. 2017. "Mistaken Play in the Deferred Acceptance Algorithm: Implications for Positive Assortative Matching." American Economic Review: Papers $\&$ Proceedings 107 (5): 225-29.

Rees-Jones, Alex, and Samuel Skowronek. 2018. "An experimental investigation of preference misrepresentation in the residency match." Proceedings of the National Academy of Sciences 115 (45): 11471-11476.

Roth, Alvin E. 1982. "The economics of matching: Stability and incentives." Mathematics of Operations Research 7 (4): 617-628.

Roth, Alvin E., Tayfun Sönmez, and M. Utku Ünver. 2004. "Kidney Exchange." The Quarterly Journal of Economics 119 (2): 457-488.

Ryan, James E., and Michael Heise. 2002. "The Political Economy of School Choice." Yale Law Journal 111:2043-2136.

Shapley, Lloyd, and Herbert Scarf. 1974. "On cores and indivisibility." Journal of Mathematical Economics 1 (1): 23-37.

Stieger, Stefan, and Ulf-Dietrich Reips. 2016. "A limitation of the Cognitive Reflection Test: familiarity." PeerJ 4:e2395.

Thibaut, John, and Laurens Walker. 1978. "A Theory of Procedure." California Law Review 66:541-566.

Tilly, Jan, and Nick Janetos. 2018. "Package 'matchingR'." Working Paper.

Westkamp, Alexander. 2013. "An analysis of the German university admissions system." Economic Theory 53 (3): 561-589. 


\section{Appendix}

\section{A.1. Procedural information in US public school districts}

The Office of the Superintendent of the Boston Public Schools makes the following recommendation: "BPS strongly encourages families to rank all the schools that appear on their choice list. We suggest ranking them in your true order of preference. Choosing more schools, especially schools at which your child has a sibling priority, means a greater possibility of assignment."30

The Cleveland Metropolitan School District provides the following information in its "Mythbusters" application guide: "Schools should always be ranked in the true order of where the student wants to go. Schools should not be ranked in any other way. The selection process is designed to give your child the highest choice for which he or she qualifies. (...) It does not matter when you submit your application as long as it is before the application deadline. The selection process does not take place until after the application deadline." ${ }^{31}$

The Indianapolis Public Schools provide the following information: "The best way to get your top choice school is to rank schools based on your personal preference from most preferred (number 1) to least preferred (number 10) and to apply in the first round. (...) [Y]ou should rank your choices in the order you want them. If there is no room in your first choice, Enroll Indy will try to get you into your second choice, and so on." 32

The Newark Public Schools provide the following information: "When a student does not receive his or her first choice, the matching process will move down the student's list of schools in order to place the student in his or her highest-ranked school that has available seats. (...) Siblings who are applying at the same time receive priority to be matched together. Families with multiple applicants who are applying to attend a new school together should list the schools for all students in

30. See <https://www.bostonpublicschools.org/Page/6489>, last accessed on August 5, 2019.

31. See <http://www.clevelandmetroschools.org/chooseCMSD\#learn>, last accessed on August 5, 2019.

32. See <https://enrollindy.org/faq/>, last accessed on August 5, 2019. 
the family in the same order and indicate on the application that they would like to keep their children in the same school." 33

The Orleans Parish School Board in New Orleans provides the following information: "The number of choices you list on your application does not affect the likelihood of you getting one of your top choices. We seek to place all families at their highest-ranked school with seats available, based on family preference and each school's priorities. [...] OneApp assigns applicants to their single best offer. This means that a student's school assignment is the highest ranked school that had a seat available for them. (...) [T]here is no advantage to applying early because all applications are processed after the deadline. By processing all applications at once, families who are unable to submit their applications earlier, or families who are using the full application window to go on school visits and do research on their options, are not at a disadvantage."34

\section{A.2. Simulation ( $R$ code)}

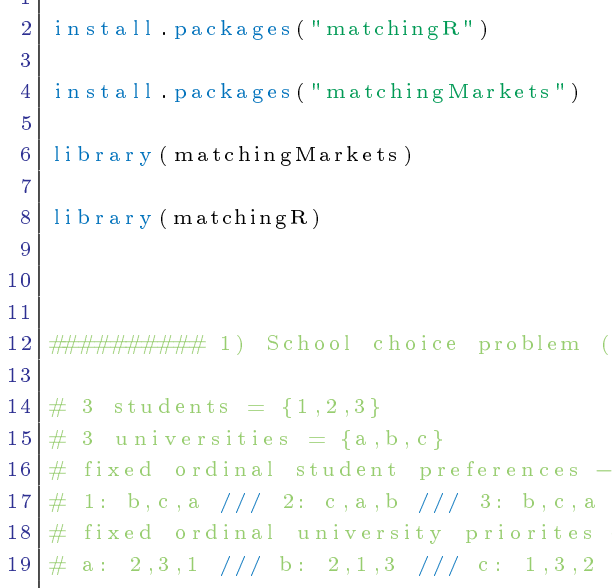

33. See <https://sites.google.com/a/nps.k12.nj.us/ue-school-resources/resources/guidebook>, last accessed on August 5, 2019.

34. See <https://enrollnola.org/resources/faqs/>, last accessed on August 5, 2019. 


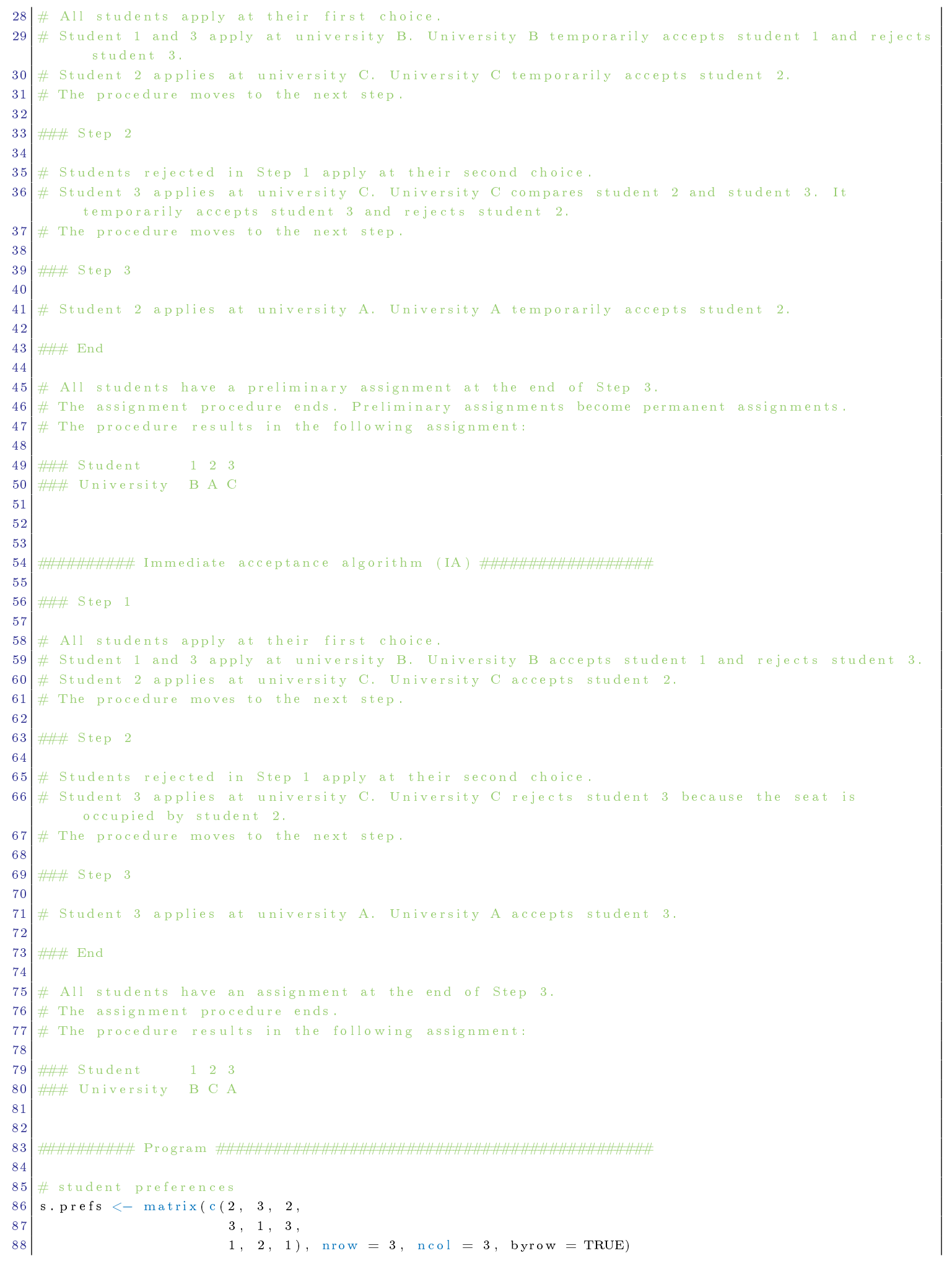




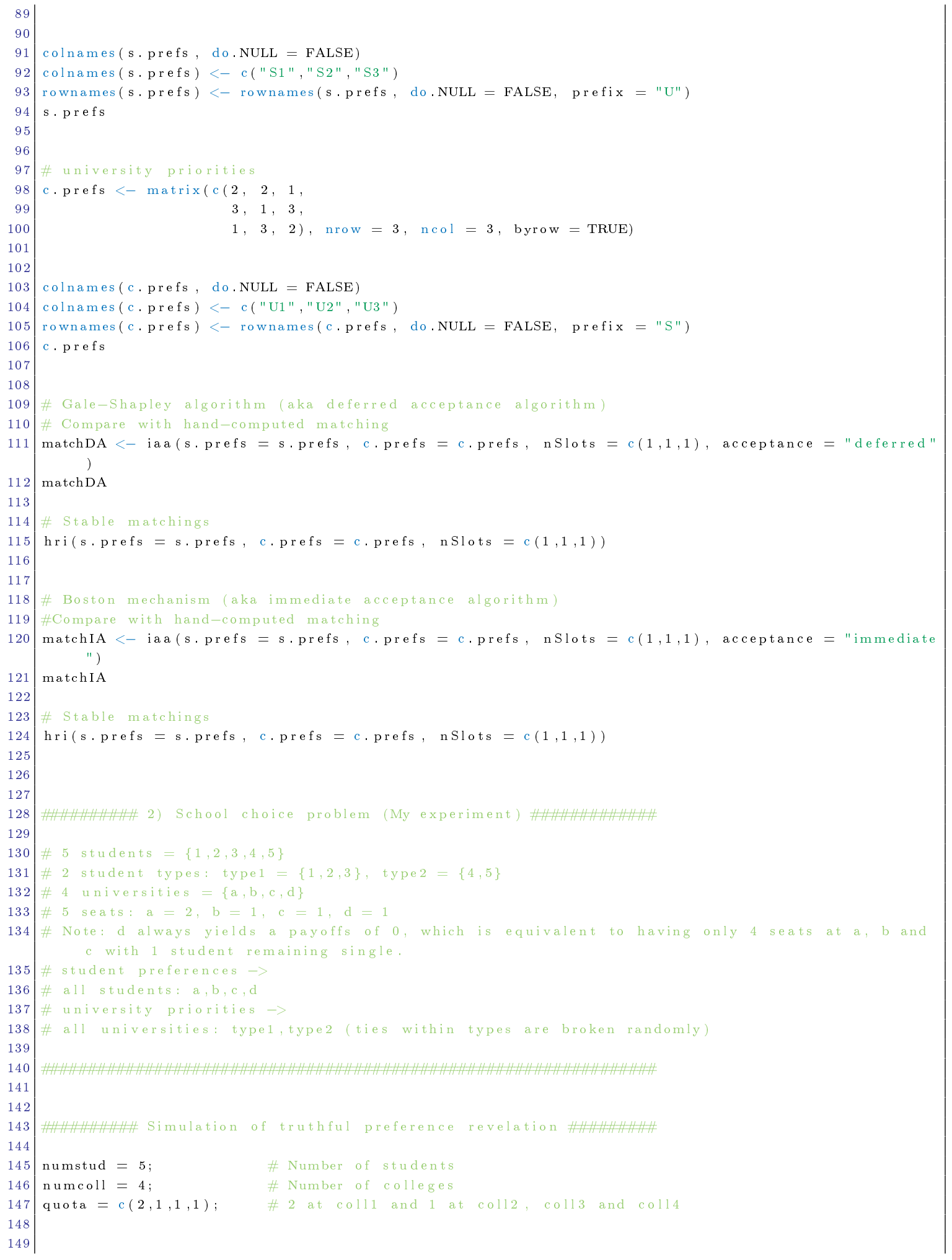




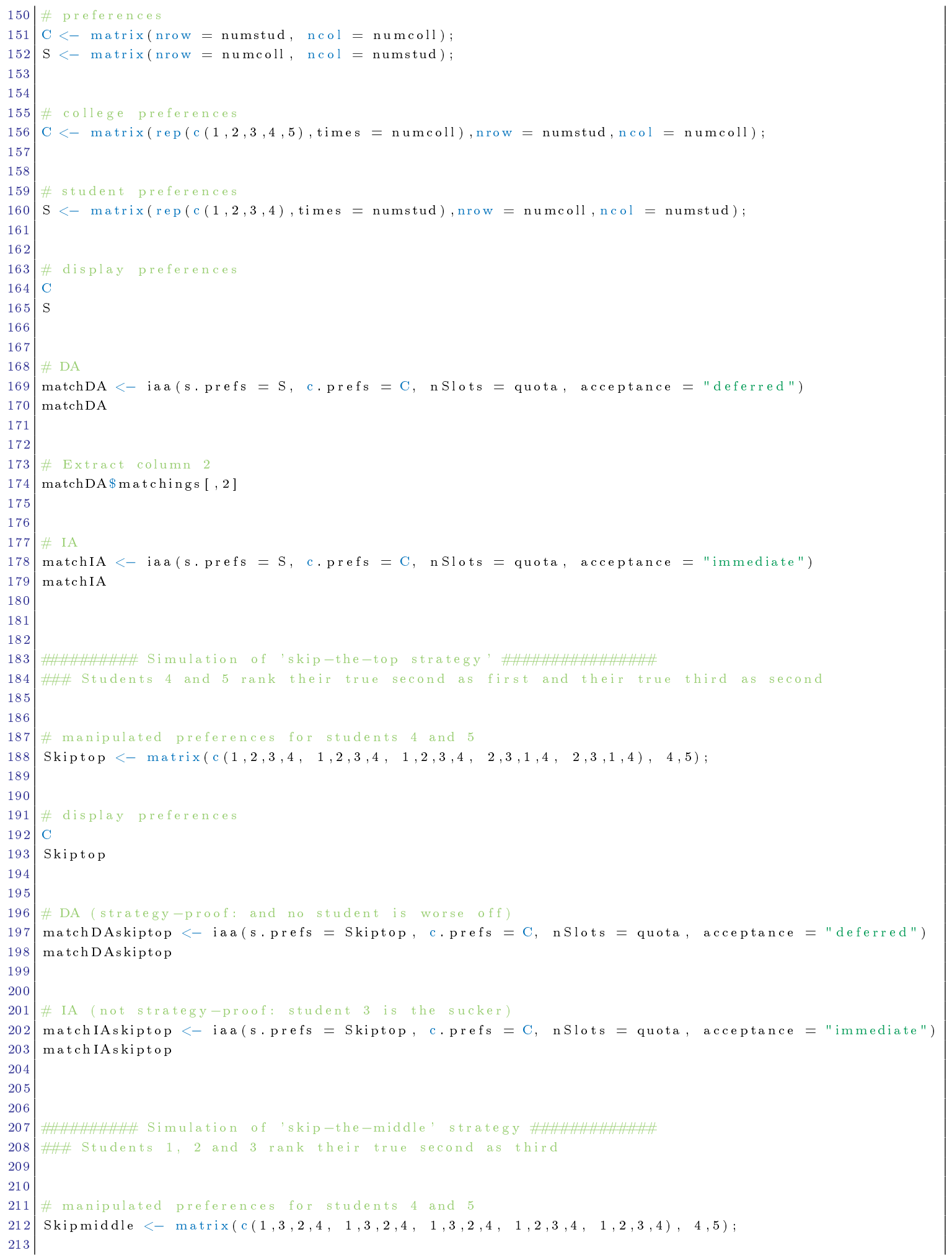




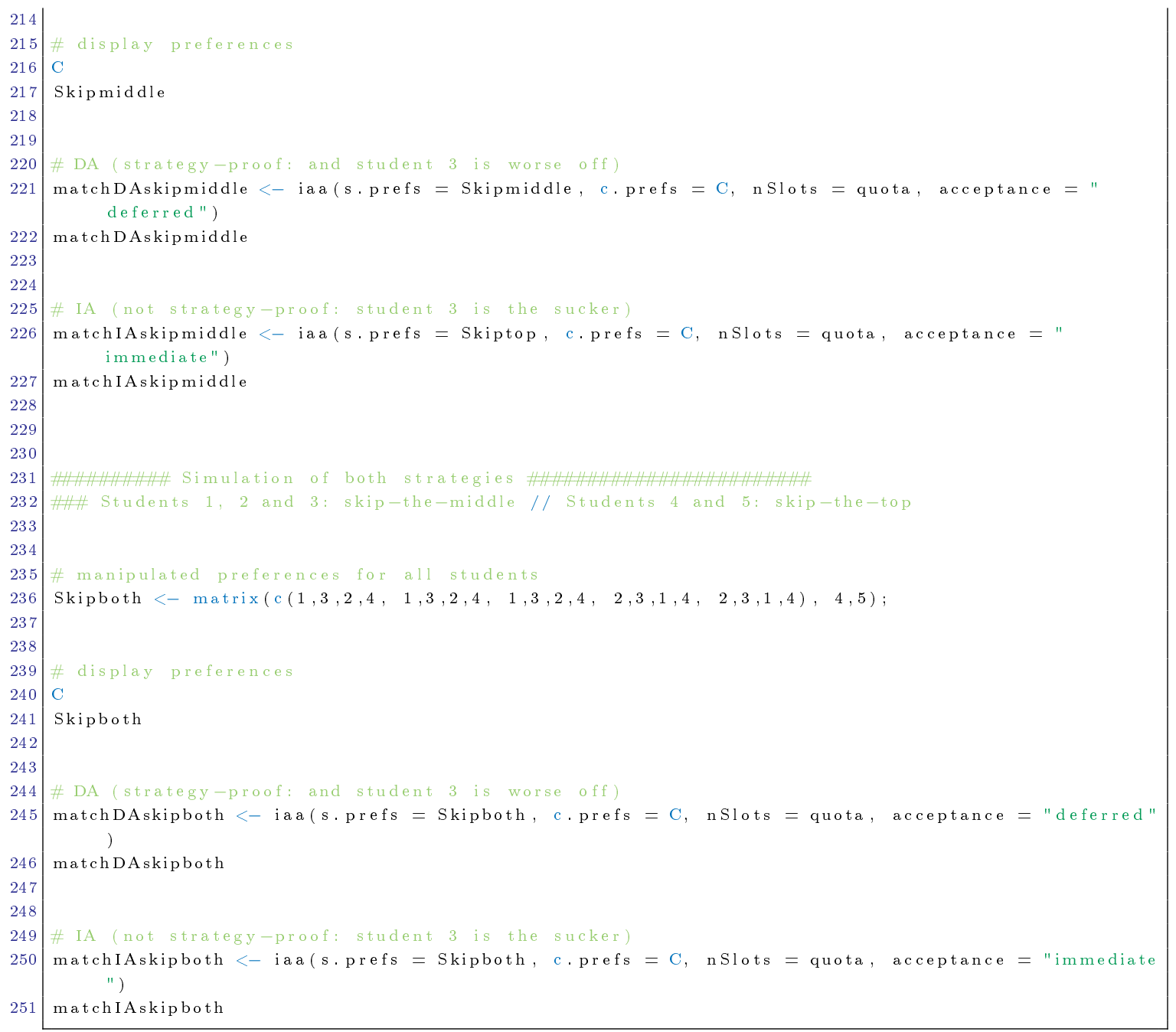

\section{A.3. Experiment ( $R$ code)}

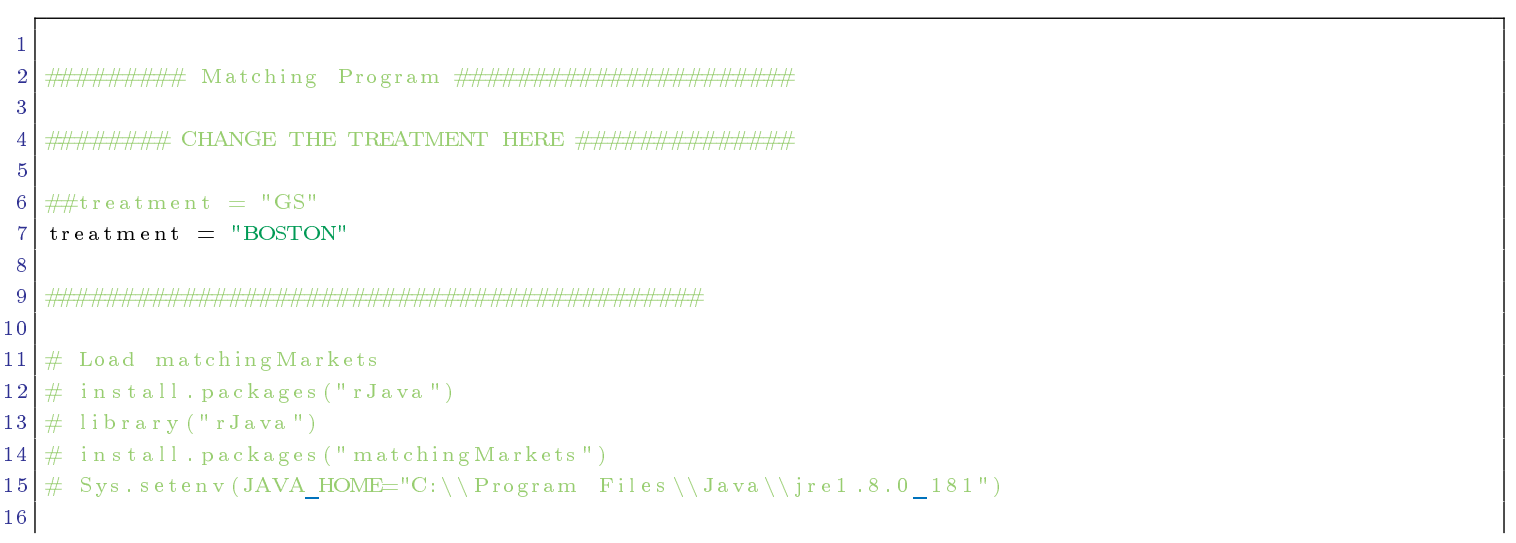




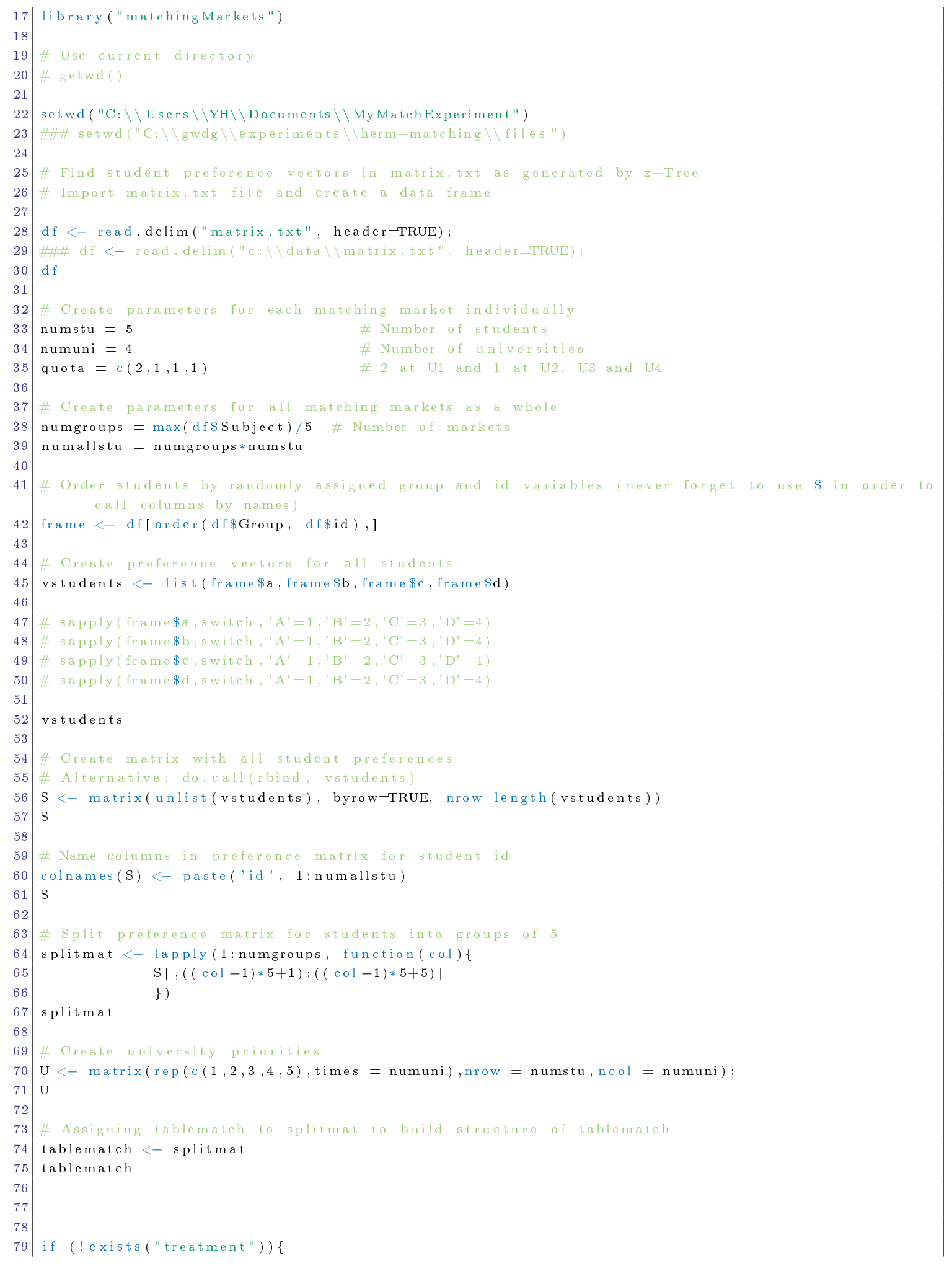




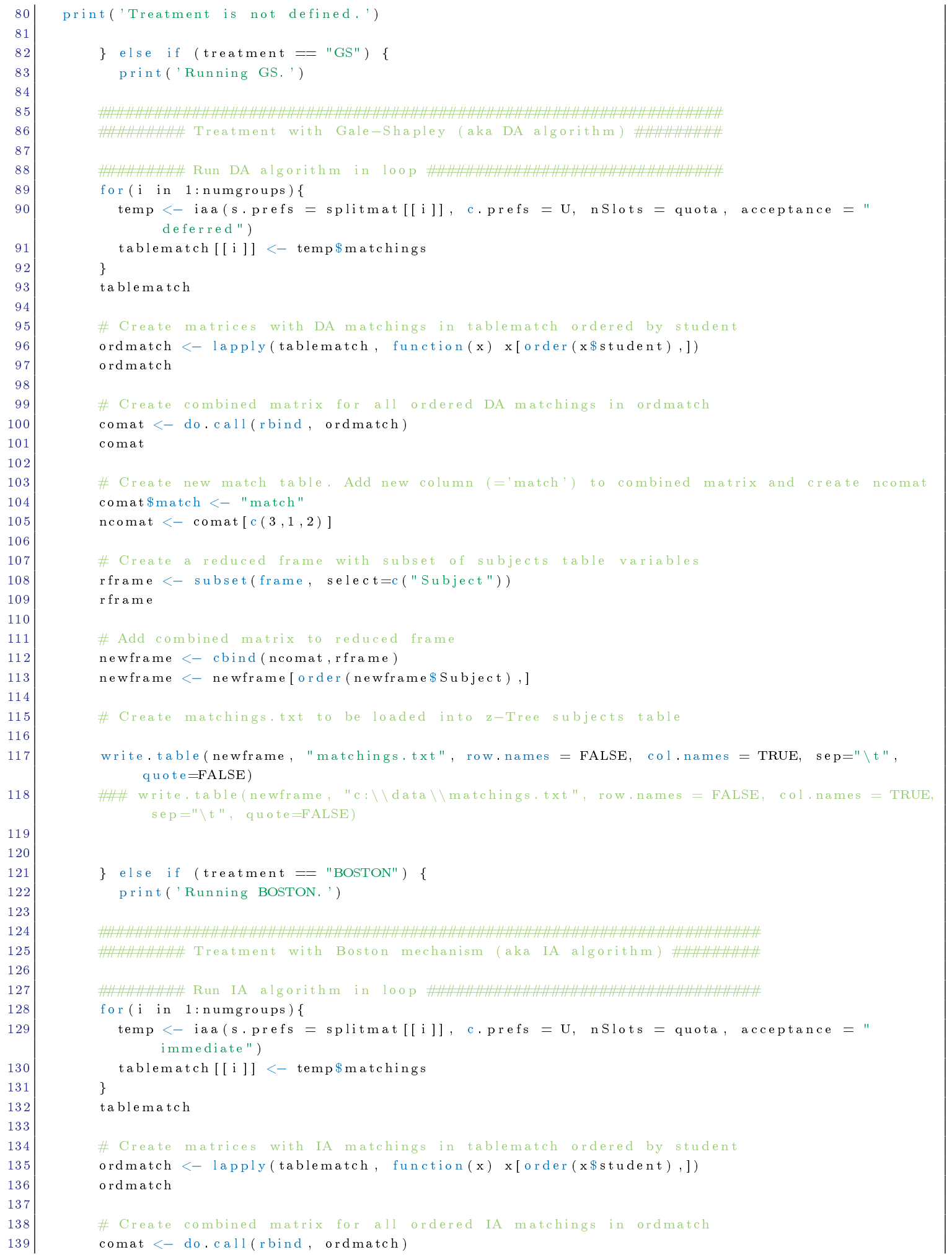




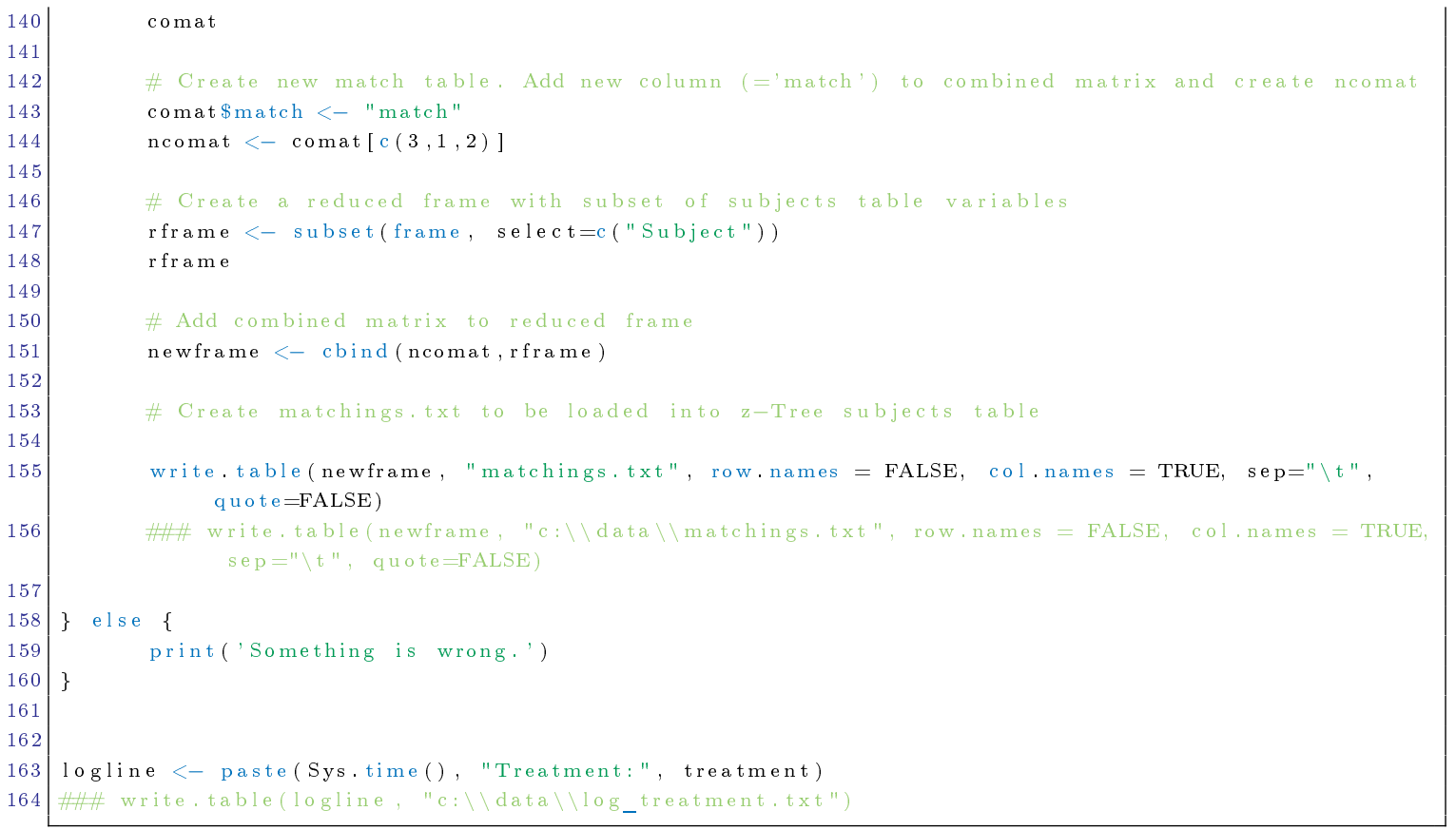

\section{A.4. Additional results}

This subsection provides an overview of some additional results. All p-values are those of a Fisher's exact test if not otherwise reported.

\section{A.4.1. Treatment effects under the BOS mechanism}

Table 9 reports the treatment effects under the BOS mechanism with the baseline BOS mechanism as the reference category in a multinomial logistic regression. In the treatment with combined information, the negative effect on truth-telling is close to marginally significant for Type- 1 and Type- 2 students $(p=0.128$ and $p=$ 0.121). However, the effects on both dropping strategies are clearly insignificant. In sum, strategic and combined information seem to reduce truth-telling, without a positive effect on the adoption of equilibrium strategies.

\section{A.4.2. Effect of risk aversion on strategies}

Table 10 reports the effect of risk aversion on strategies. Under the baseline BOS mechanism, risk aversion explains a decrease in truth-telling and an increase in 
Table 9: Treatment effects on strategies

\begin{tabular}{lccc}
\hline Strategy & Truth & Skip-the-middle & Skip-the-top \\
\hline $\begin{array}{l}\text { Ref. cat.: BOS Base } \\
\text { BOS StratInfo }\end{array}$ & & \\
Type 1 & $-0.262^{*}$ & 0.107 & 0.155 \\
& $(0.138)$ & $(0.117)$ & $(0.109)$ \\
Type 2 & -0.076 & 0.091 & -0.015 \\
& $(0.138)$ & $(0.087)$ & $(0.158)$ \\
BOS Combined & & & \\
Type 1 & -0.232 & 0.092 & 0.140 \\
& $(0.153)$ & $(0.128)$ & $(0.121)$ \\
Type 2 & -0.167 & 0.083 & 0.083 \\
& $(0.108)$ & $(0.080)$ & $(0.134)$ \\
\hline
\end{tabular}

${ }^{* * *} p<0.01 ;{ }^{* *} p<0.05 ;{ }^{*} p<0.1$

Multinomial logit regression with interaction between treatment and type. Standard errors in parentheses. Treatment coefficients are reported as average marginal treatment effects. All columns report estimates of one and the same multinomial logit regression. Each cell can be interpreted as the difference in the probability of adopting one of the reported strategies (categorical DV: Truth, Skip-the-middle, Skip-the-top) between the respective treatment and BOS Base (reference category) for Type-1 students (top panel) and Type-2 students (bottom panel). The category Other was dropped due to singularity. 
skip-the-top rates. Under the BOS mechanism with combined information, however, risk aversion yields a decrease in truth-telling and an increase in other (nonequilibrium) strategies. One potential explanation for the first result is that risk averse students may have been afraid of foregoing a potential seat at university A. This result is in line with the rationale of risk aversion. One potential explanation for the second result is that combined information may have spurred risk averse students to seek for even better strategies to obviate a foregone seat. This result points at a context-specific instance of bounded rationality and suggests that detailed information about the assignment procedure may trigger backfiring effects for risk averse applicants. ${ }^{35}$

\section{A.4.3. Treatment effects on stability and welfare}

Table 11 reports the treatment effects on stability. Under the GS mechanism, strategic and combined information yield a strong increase in stability levels relative to the baseline. Under the BOS mechanism, a strong reduction of stability levels can be observed in all treatments. This result highlights that, even under the GS mechanism, stability cannot be achieved without adequately informing applicants about the best response (truth-telling).

Table 12 presents the descriptive statistics of the outcome obtained in each treatment. The results on preference manipulations under the BOS mechanism indicate that Type-1 students suffered welfare losses, while Type-2 students benefited from considerable welfare gains. This results from a redistribution of seats at university B from Type-1 students to Type-2 students. Using the conservative estimate of a Fisher's exact test, I find that the fraction of Type- 1 students matched with university B is not lower under the BOS mechanism than under the GS mechanism $(p=0.118)$. However, I find that Type-2 students are matched with university B more frequently under the BOS mechanism than under the GS mechanism $(p=0.011)$.

35. The results also show that none of the strategies can be explained through experience with the BOS mechanism. Accordingly, students who are familiar with the German university admissions procedure for medical school are not more likely to adopt an equilibrium strategy 
Table 10: Effect of risk aversion on strategies

\begin{tabular}{ccccc}
\hline Strategy & Truth & Skip-the-middle & Skip-the-top & Other \\
\hline GS Base & & & & \\
xRisk aversion & 0.175 & -0.011 & -0.144 & -0.020 \\
& $(0.144)$ & $(0.048)$ & $(0.134)$ & $(0.115)$ \\
GS StratInfo & & & & \\
xRisk aversion & -0.032 & $<0.001$ & 0.096 & -0.065 \\
& $(0.118)$ & $(<0.001)$ & $(0.090)$ & $(0.080)$ \\
GS Combined & & & & \\
xRisk aversion & 0.091 & -0.047 & 0.133 & -0.177 \\
BOS Base & $(0.162)$ & $(0.076)$ & $(0.093)$ & $(0.137)$ \\
xRisk aversion & $-0.296^{* *}$ & 0.126 & & $-0.263^{*}$ \\
BOS StratInfo & $(0.143)$ & $(0.118)$ & $(0.155)$ & $(0.078)$ \\
xRisk aversion & 0.054 & -0.079 & -0.140 & 0.165 \\
& $(0.158)$ & $(0.127)$ & $(0.159)$ & $(0.124)$ \\
BOS Combined & & & & \\
xRisk aversion & -0.015 & 0.030 & $-0.317^{* *}$ & $0.302^{* * *}$ \\
& $(0.123)$ & $(0.093)$ & $(0.130)$ & $(0.089)$ \\
\hline
\end{tabular}

${ }^{* * *} p<0.01 ;{ }^{* *} p<0.05 ;^{*} p<0.1$

Multinomial logit regression with interaction between treatment and risk aversion. Standard errors in parentheses. All coefficients are reported as average marginal effects. All columns report estimates of one and the same multinomial logit regression. Each cell can be interpreted as the difference in the probability of adopting one of the reported strategies (categorical DV: Truth, Skip-the-middle, Skip-the-top, Other) generated by an increase in risk aversion in each treatment. 
Table 11: Treatment effects on stability

\begin{tabular}{|c|c|c|}
\hline & \multicolumn{2}{|c|}{ Stability } \\
\hline \multicolumn{3}{|c|}{ Ref. cat.: GS Base } \\
\hline \multirow{2}{*}{ GS StratInfo } & $0.651^{* * *}$ & $0.650^{* * *}$ \\
\hline & $(0.072)$ & $(0.071)$ \\
\hline \multirow[t]{2}{*}{ GS Combined } & $0.529^{* * *}$ & $0.523^{* * *}$ \\
\hline & $(0.088)$ & $(0.088)$ \\
\hline \multirow[t]{2}{*}{ BOS Base } & $-0.323^{* * *}$ & $-0.323^{* * *}$ \\
\hline & $(0.072)$ & $(0.072)$ \\
\hline \multirow[t]{2}{*}{ BOS StratInfo } & $-0.203^{* *}$ & $-0.202^{* *}$ \\
\hline & $(0.088)$ & $(0.087)$ \\
\hline \multirow[t]{2}{*}{ BOS Combined } & $-0.323^{* * *}$ & $-0.324^{* * *}$ \\
\hline & $(0.072)$ & $(0.072)$ \\
\hline \multirow[t]{2}{*}{ Risk aversion } & & 0.045 \\
\hline & & $(0.041)$ \\
\hline$N$ & 235 & 235 \\
\hline \multicolumn{3}{|c|}{${ }^{* * *} p<0.01 ;{ }^{* *} p<0.05 ;^{*} p<0.1$} \\
\hline \multicolumn{3}{|c|}{$\begin{array}{l}\text { Logit regression. Standard errors in parentheses. Each column } \\
\text { corresponds to a different logit regression. Treatment coefficients } \\
\text { are reported as average marginal treatment effects. Stability is a } \\
\text { dummy variable taking value } 1 \text { if the matching in the respective }\end{array}$} \\
\hline
\end{tabular}

A multinomial logistic regression corroborates this result (Table 13). One potential explanation is that many Type- 1 students are unable to solve the highly complex decision problem under the baseline BOS mechanism and fend off the skip-the-top strategy adopted by Type-2 students. The inability of Type-1 students to best respond by skipping the middle based on first-order beliefs about the behavior of Type- 2 students results in the observed redistributive effect. The strategic and the combined information treatments mitigate this redistributive effect. As a consequence, the fraction of Type- 1 students matched with university B is higher in these treatments than under the baseline BOS mechanism. This sugthan students who are unfamiliar with the procedure. 
Table 12: Matchings

\begin{tabular}{cccccccc}
\hline & \multicolumn{3}{c}{ GS } & & \multicolumn{3}{c}{ BOS } \\
\cline { 2 - 5 } \cline { 6 - 8 } & Base & StratInfo & Combined & & Base & StratInfo & Combined \\
\hline T1-A & $66.67 \%(2 / 3)$ & $66.67 \%(2 / 3)$ & $66.67 \%(2 / 3)$ & & $66.67 \%(2 / 3)$ & $66.67 \%(2 / 3)$ & $66.67 \%(2 / 3)$ \\
T1-B & $29.63 \%(1 / 3)$ & $33.33 \%(1 / 3)$ & $29.17 \%(1 / 3)$ & & $9.52 \%(0)$ & $20.83 \%(0)$ & $23.81 \%(0)$ \\
T1-C & $0 \%(0)$ & $0 \%(0)$ & $0 \%(0)$ & & $14.29 \%(1 / 3)$ & $8.33 \%(1 / 3)$ & $9.52 \%(1 / 3)$ \\
T1-D & $3.70 \%(0)$ & $0 \%(0)$ & $4.17 \%(0)$ & & $9.52 \%(0)$ & $4.17 \%(0)$ & $0 \%(0)$ \\
\hline T2-A & $0 \%(0)$ & $0 \%(0)$ & $0 \%(0)$ & & $0 \%(0)$ & $0 \%(0)$ & $0 \%(0)$ \\
T2-B & $5.56 \%(0)$ & $0 \%(0)$ & $6.25 \%(0)$ & & $35.71 \%(1 / 2)$ & $18.75 \%(1 / 2)$ & $14.29 \%(1 / 2)$ \\
T2-C & $50.00 \%(1 / 2)$ & $50 \%(1 / 2)$ & $43.75 \%(1 / 2)$ & & $28.57 \%(0)$ & $37.50 \%(0)$ & $35.71 \%(0)$ \\
T2-D & $44.44 \%(1 / 2)$ & $50 \%(1 / 2)$ & $50 \%(1 / 2)$ & & $35.71 \%(1 / 2)$ & $43.75 \%(1 / 2)$ & $50 \%(1 / 2)$ \\
\hline
\end{tabular}

T1-A denotes that a Type-1 student was matched with university A. Percentages report the fraction of students of a certain type matched with a certain university. Equilibrium prediction in parentheses.

gests that information about the strategic properties of the mechanism facilitates sensible defense strategies for students facing a very complex decision problem and even entails some convergence of the outcome obtained under the BOS mechanism and the equilibrium outcome of the GS mechanism.

\section{A.4.4. Cognitive abilities}

Table 14 reports the effect of cognitive abilities on strategies in each treatment. Overall, the results show that applicants with higher cognitive abilities benefit from strategic information, while applicants with lower cognitive abilities benefit from combined information. This points at a potential trade-off between simplicity (information about sensible application strategies, with higher benefits to applicants with higher cognitive abilities) and full transparency (information about the assignment procedure and sensible application strategies, with higher benefits to applicants with lower cognitive abilities). 
Table 13: Treatment effects on matchings

\begin{tabular}{|c|c|c|c|c|}
\hline University & $\mathrm{A}$ & B & $\mathrm{C}$ & $\mathrm{D}$ \\
\hline \multicolumn{5}{|c|}{ Ref. cat.: GS Base } \\
\hline \multicolumn{5}{|c|}{ GS StratInfo } \\
\hline \multirow[t]{2}{*}{ Type 1} & $<0.001$ & 0.037 & $<0.001$ & -0.037 \\
\hline & $(0.132)$ & $(0.130)$ & $(<0.001)$ & $(0.036)$ \\
\hline \multirow[t]{2}{*}{ Type 2} & $<0.001$ & -0.056 & $<0.001$ & 0.056 \\
\hline & $(<0.001)$ & $(0.054)$ & $(0.172)$ & $(0.171)$ \\
\hline \multicolumn{5}{|c|}{ GS Combined } \\
\hline \multirow[t]{2}{*}{ Type 1} & $<0.001$ & -0.005 & 0.042 & -0.037 \\
\hline & $(0.132)$ & $(0.128)$ & $(0.041)$ & $(0.036)$ \\
\hline \multirow[t]{2}{*}{ Type 2} & $<0.001$ & 0.007 & -0.063 & 0.056 \\
\hline & $(<0.001)$ & $(0.081)$ & $(0.171)$ & $(0.171)$ \\
\hline \multicolumn{5}{|l|}{ BOS Base } \\
\hline \multirow[t]{2}{*}{ Type 1} & $<0.001$ & $-0.201^{*}$ & $0.143^{*}$ & 0.058 \\
\hline & $(0.137)$ & $(0.109)$ & $(0.076)$ & $(0.074)$ \\
\hline \multirow[t]{2}{*}{ Type 2} & $<0.001$ & $0.302^{* *}$ & -0.214 & -0.087 \\
\hline & $(<0.001)$ & $(0.139)$ & $(0.169)$ & $(0.174)$ \\
\hline \multicolumn{5}{|c|}{ BOS StratInfo } \\
\hline \multirow[t]{2}{*}{ Type 1} & $<0.001$ & -0.088 & 0.083 & 0.005 \\
\hline & $(0.132)$ & $(0.121)$ & $(0.056)$ & $(0.055)$ \\
\hline \multirow[t]{2}{*}{ Type 2} & $<0.001$ & 0.132 & -0.125 & -0.007 \\
\hline & $(<0.001)$ & $(0.112)$ & $(0.169)$ & $(0.171)$ \\
\hline \multicolumn{5}{|c|}{ BOS Combined } \\
\hline \multirow[t]{2}{*}{ Type 1} & $<0.001$ & -0.058 & 0.095 & -0.037 \\
\hline & $(0.137)$ & $(0.128)$ & $(0.064)$ & $(0.036)$ \\
\hline \multirow[t]{2}{*}{ Type 2} & $<0.001$ & 0.087 & -0.143 & 0.056 \\
\hline & $(<0.001)$ & $(0.108)$ & $(0.174)$ & (0.178) \\
\hline
\end{tabular}

${ }^{* * *} p<0.01 ;{ }^{* *} p<0.05 ;^{*} p<0.1$

Multinomial logit regression with interaction between treatment and type. Standard errors in parentheses. Treatment coefficients are reported as average marginal treatment effects. All columns report estimates of one and the same multinomial logit regression. Each cell can be interpreted as the difference in the probability of being matched to one of the universities (categorical DV: $A, B, C, D$ ) between the respective treatment and GS Base (reference category) for Type-1 students (top panel) and Type-2 students (bottom panel). 
Table 14: Effect of cognitive abilities on strategies

\begin{tabular}{|c|c|c|c|c|}
\hline Strategy & Truth & Skip-the-middle & Skip-the-top & Other \\
\hline \multicolumn{5}{|c|}{ Ref. cat.: GS Base } \\
\hline \multicolumn{5}{|c|}{ GS StratInfo } \\
\hline \multirow[t]{2}{*}{ LoCRT } & $0.262^{* *}$ & $<0.001$ & -0.125 & $-0.137^{*}$ \\
\hline & $(0.121)$ & $(<0.001)$ & $(0.106)$ & $(0.083)$ \\
\hline \multirow[t]{2}{*}{ HiCRT } & $0.404^{* * *}$ & -0.059 & $-0.294^{* * *}$ & -0.051 \\
\hline & $(0.147)$ & $(0.057)$ & $(0.111)$ & $(0.124)$ \\
\hline \multicolumn{5}{|c|}{ GS Combined } \\
\hline \multirow[t]{2}{*}{ LoCRT } & $0.280^{* *}$ & 0.037 & $-0.213^{* *}$ & -0.105 \\
\hline & $(0.116)$ & $(0.036)$ & $(0.090)$ & $(0.088)$ \\
\hline \multirow[t]{2}{*}{ HiCRT } & $0.376^{* *}$ & -0.059 & -0.140 & $-0.176^{*}$ \\
\hline & $(0.157)$ & $(0.057)$ & $(0.149)$ & $(0.092)$ \\
\hline \multicolumn{5}{|l|}{ BOS Base } \\
\hline \multirow[t]{2}{*}{ LoCRT } & -0.121 & 0.050 & 0.150 & -0.079 \\
\hline & $(0.145)$ & $(0.049)$ & $(0.137)$ & $(0.099)$ \\
\hline \multirow[t]{2}{*}{ HiCRT } & 0.129 & 0.075 & -0.027 & $-0.176^{*}$ \\
\hline & $(0.175)$ & $(0.105)$ & $(0.159)$ & $(0.092)$ \\
\hline \multicolumn{5}{|c|}{ BOS StratInfo } \\
\hline \multirow[t]{2}{*}{ LoCRT } & -0.203 & 0.105 & 0.118 & -0.021 \\
\hline & $(0.145)$ & $(0.070)$ & $(0.138)$ & $(0.111)$ \\
\hline \multirow[t]{2}{*}{ HiCRT } & -0.185 & $0.179^{*}$ & 0.087 & -0.081 \\
\hline & $(0.156)$ & $(0.109)$ & $(0.153)$ & $(0.112)$ \\
\hline \multicolumn{5}{|c|}{ BOS Combined } \\
\hline \multirow[t]{2}{*}{ LoCRT } & $-0.299^{* *}$ & $0.136^{*}$ & 0.159 & 0.003 \\
\hline & $(0.133)$ & $(0.073)$ & $(0.133)$ & $(0.110)$ \\
\hline \multirow[t]{2}{*}{ HiCRT } & -0.240 & 0.095 & 0.167 & -0.023 \\
\hline & $(0.168)$ & $(0.115)$ & $(0.177)$ & $(0.136)$ \\
\hline
\end{tabular}

${ }^{* * *} p<0.01 ;{ }^{* *} p<0.05 ;{ }^{*} p<0.1$

Multinomial logit regression with interaction between treatment and cognitive reflection abilities. Standard errors in parentheses. All coefficients are reported as average marginal effects. All columns report estimates of one and the same multinomial logit regression. LoCRT (HiCRT) is an ordinal variable clustering participants who provided two or less correct answers (three or more correct answers) to the 6-item cognitive reflection test. Each cell can be interpreted as the difference in the probability of adopting one of the reported strategies (categorical DV: Truth, Skip-the-middle, Skip-the-top, Other) between the respective treatment and GS Base (reference category). 


\section{A.5. Instructions}

\section{INSTRUCTIONS}

Welcome to this experiment in decision making. Please read the following instructions carefully. You can earn money in this experiment. Your earnings depend on your decisions, on the decisions of the other participants, and on a lottery. At the end of the experiment, the total amount of money earned will be paid to you in cash. In addition, you will receive 5 Euro for participating in the experiment. The payment is private and confidential.

During the experiment, some monetary amounts are not quoted in Euros, but in Points. At the end of the experiment, Points earned during the experiment will be converted into Euros, where:

1 Point $=0.10$ Euro.

The experiment consists of two parts. All participants receive the same instructions. All decisions in this experiment are made anonymously. You are not allowed to use your cell phones or electronic devices during the experiment. Communicating with other participants is not permitted throughout the experiment. If you do not comply with these rules, you will be excluded from the experiment and lose all earnings.

It is important that you understand the instructions before you start the experiment. If you have questions or need assistance, please raise your hand. We will then help you at your desk.

\section{PART 1}

In Part 1 of the experiment, you will take part in a simulated procedure to assign university seats to students. You and the other participants take the role of applicants, from now on referred to as students.

Each student applies for a seat at university. In order to apply, each student has to indicate, which university she prefers. If a student, for example, prefers university A over university B, we will refer to this as a preference for A over B. Each student orders her preferences for universities on a list. This list will be referred to as a rank-order list. 
Your earnings in part 1 depend on the university you are admitted to. A centralized assignment procedure will determine who receives a seat at which university. The outcome of this procedure depends on the rank-order lists submitted by you and the other students.

\section{Students}

At the beginning of the experiment, groups of five students will be determined randomly. A lottery will determine which group you are assigned to. Your decisions only affect you and the other students in your group.

There are two kinds of students in each group: Type 1 and Type 2. There are three students of Type 1 (= Type- 1 students) and two students of Type 2 (= Type-2 students). Your type will be determined randomly before the procedure starts. We will inform you about the type that has been assigned to you.

\section{Available seats}

There are five available seats in each group. This means there is one seat available for each student in your group. The seats are distributed over four universities: A, B, C and D. University A has two seats. University B, C and D have one seat each.

\section{Priorities}

Each university prefers Type- 1 students over Type- 2 students. We refer to this as a priority of Type- 1 students over Type-2 students. The priority that universities give to students of the same type will be determined randomly. This means that a lottery will determine the priorities of Type-1 students amongst each other and the priorities of Type-2 students amongst each other.

The priorities of universities are depicted in the table below.

All universities prefer:

$$
\text { Type } 1 \text { (3 Students) over Type } 2 \text { (2 Students) }
$$

\section{Earnings}

A centralized assignment procedure will determine who receives a seat at which university. The outcome of this procedure depends on the rank-order lists submitted by you and the other students in your group.

Your earnings depend on the university you are admitted to. Your potential earnings are sum- 
marized in the table below.

\begin{tabular}{l|l|l|l} 
University A & University B & University C & University D \\
\hline $\begin{array}{l}2 \text { seats } \\
100 \text { Points }\end{array}$ & $\begin{array}{l}\text { 1 seat } \\
\text { 6 Points }\end{array}$ & $\begin{array}{l}\text { 1 seat } \\
\text { 25 Points }\end{array}$ & 1 seat \\
\end{tabular}

For example, if you are admitted at university A, you earn 100 Points. However, if you are admitted at university $\mathrm{D}$, you earn 0 Points.

\section{$\underline{\text { Decision }}$}

In order to apply for a seat, you will submit an application form with a rank-order list indicating your preferences for all universities. The form contains four boxes representing the order of your preferences: First choice, Second choice, Third choice and Fourth choice. Each box can be filled with the name of the respective university: A, B, C or D.

You have to rank all four universities. This ranking determines the order, in which your applications are sent to the universities. You are free to choose the order, in which you rank universities. When you are done, please confirm your rank-order list by clicking "Submit".

\section{Assignment procedure}

Once you have ranked all universities and submitted your rank-order list, the computer will automatically implement the procedure determining the assignment of students to available seats.

We will use a procedure that takes into account the priorities, your preferences and the preferences of the other students.

\section{[1 Baseline DA Treatment]}

The computer will go through the following steps for the students:

\section{Step 1}

- Each student applies at the university she ranked as first choice on her rank-order list.

- If more students apply at a university than the university has seats, the university preliminarily admits students in the order of their priority up to capacity. Students who do not receive a seat are permanently rejected at the respective university. 
Step 2

- Every student who has been admitted preliminarily in the previous step (= Step 1) continues to apply at the university that is ranked as first choice on her rankorder list in the current step (= Step 2). Every student who has been rejected in the previous step applies at the university that is ranked next on her rank-order list in the current step.

- Each university compares the applications in the current step (=Step 2) with the applications from students preliminary admitted in the previous step (= Step 1). Each university preliminarily admits students in the order of their priority up to capacity. This means: Preliminary admissions from the previous step are revoked if students with a higher priority apply at the respective university in the current step. Students who do not receive a seat are permanently rejected at the respective university. Further steps

- The procedure continues according to these rules in each following step.

End

- The procedure ends when no more applications are rejected. Preliminary assignment then becomes permanent assignment: Each student is assigned a seat at the university that last admitted her.

At the end of the procedure, we will inform you about the university you were finally assigned to.

\section{Example}

The following example illustrates how the procedure works. Please note that this example is not an indicator for how you should behave in the experiment.

In this example, there are three students (S1, S2, and S3) and three universities (A, B and C). Each university has 1 seat. Students submit the following rank-order lists for universities:

\begin{tabular}{l|lll} 
Student & S1 & S2 & S3 \\
\hline First choice & B & C & B \\
Second choice & C & A & C \\
Third choice & A & B & A
\end{tabular}

Universities have the following priorities over students: 


\begin{tabular}{l|lll} 
University & A & B & C \\
\hline First priority & S2 & S2 & S1 \\
Second priority & S3 & S1 & S3 \\
Third priority & S1 & S3 & S2
\end{tabular}

The procedure is carried out as follows:

\section{Step 1}

- Each student applies at the university she ranked as first choice on her rank-order list.

- S1 and S3 apply at university B. University B temporarily admits S1 (second priority) and rejects $\mathrm{S} 3$ (third priority).

- S2 applies at university C. University C temporarily admits S2.

- The procedure moves to the next step.

Step 2

- Every student who has been rejected in Step 1 applies at the university that is ranked next on her rank-order list.

- S3 applies at university C. University C compares S2 and S3. It temporarily admits S3 (second priority) and rejects S2 (third priority). This means: The temporary admission of $\mathrm{S} 2$ is revoked.

- The procedure moves to the next step.

Step 3

- S2 applies at university A. University A temporarily admits S2.

End

- All students have a preliminary assignment at the end of Step 3.

- The assignment procedure ends. Preliminary assignment then becomes permanent assignment.

The procedure results in the following assignment:

\section{[2 Baseline IA Treatment]}




$\begin{array}{llll}\text { Student } & \text { S1 } & \text { S2 } & \text { S3 } \\ \text { University } & \text { B } & \text { A } & \text { C }\end{array}$

The computer will go through the following steps for the students:

Step 1

- Each student applies at the university she ranked as first choice on her rank-order list.

- If more students apply at a university than the university has seats, the university permanently admits students in the order of their priority up to capacity. Students who are assigned a seat in Step 1 are admitted for good. For them, the assignment procedure ends. Students who do not receive a seat move to the next step.

Step 2

- Every student who has been rejected in Step 1 applies at the university that is ranked next on her application form.

- If more students apply at a university than the university has seats, the university permanently admits students in the order of their priority up to capacity. Students who are assigned a seat in Step 2 are admitted for good. For them, the assignment procedure ends. Students who do not receive a seat move to the next step.

Further steps

- The procedure continues according to these rules in each following step.

End

- The procedure ends when no more applications are rejected.

At the end of the procedure, we will inform you about the university you were assigned to.

\section{Example}

The following example illustrates how the procedure works. Please note that this example is not an indicator for how you should behave in the experiment.

In this example, there are three students (S1, S2, and S3) and three universities (A, B and C). Each university has 1 seat. Students submit the following rank-order lists for universities: 


\begin{tabular}{l|lll} 
Student & S1 & S2 & S3 \\
\hline First choice & B & C & B \\
Second choice & C & A & C \\
Third choice & A & B & A \\
University & A & B & C \\
\hline First priority & S2 & S2 & S1 \\
Second priority & S3 & S1 & S3 \\
Third priority & S1 & S3 & S2
\end{tabular}

Universities have the following priorities over students:

The procedure is carried out as follows:

Step 1

- Each student applies at the university she ranked as first choice on her rank-order list.

- S1 and S3 apply at university B. University B admits S1 (second priority) and rejects S3 (third priority).

- S2 applies at university C. University C admits S2.

- The procedure moves to the next step.

Step 2

- Every student who has been rejected in Step 1 applies at the university that is ranked next on her application form.

- S3 applies at university C. University C rejects S3 (second priority) because the seat has previously been assigned to S2 (third priority).

- The procedure moves to the next step.

Step 3

- S3 applies at university A. University A admits S3.

End

- All students have an assignment at the end of Step 3.

- The assignment procedure ends. 
The procedure results in the following assignment:

$\begin{array}{llll}\text { Student } & \text { S1 } & \text { S2 } & \text { S3 } \\ \text { University } & \text { B } & \text { C } & \text { A }\end{array}$

[3 StratInfo DA Treatment]

Procedural information

Please note that the procedure is secured against strategic decisions.

Regardless of what other students do, you will never be better off by submitting a rank-order list that does not reflect your true preferences.

This means: Your chances of being admitted to a preferred university (= yielding higher earnings) do not improve if you put a less preferred university (= yielding lower earnings) on a higher rank on the rank-order list. For example, neither Type1 students nor Type-2 students can improve their chances of being admitted to a preferred university by ranking university $A$ as their second choice and university $B$ as their first choice.

At the end of the procedure, we will inform you about the university you were assigned to.

\section{[4 StratInfo IA Treatment]}

\section{$\underline{\text { Procedural information }}$}

Please note that the procedure is not secured against strategic decisions.

Depending on what other students do, you might be better off by submitting a rank-order list that does not reflect your true preferences.

This means: Your chances of being admitted to a preferred university (= yielding higher earnings) might improve if you put a less preferred university (= yielding lower earnings) on a higher rank on the rank-order list. Type-2 students might be better off by manipulating their first choice, e.g. rank university $B$ as their first choice. In that case, Type-1 students might be better off by manipulating their second choice, e.g. rank university $C$ as their second choice. This can increase the 
chances for Type-1 students of being admitted at university $C$ if no seat at university $B$ is available any more.

At the end of the procedure, we will inform you about the university you were assigned to.

\section{[5 Combined DA Treatment]}

Baseline DA + StratInfo DA

\section{[6 Combined IA Treatment]}

Baseline IA + StratInfo IA

\section{PART 2}

In Part 2 of the experiment you will take part in two choice tasks and a survey. The instructions for this part of the experiment will appear in your screen once Part 1 is finished.

\section{Cognitive Reflection Test}

1) A bat and a ball cost 1.10 Euro in total. The bat costs 1.00 Euro more than the ball. How much does the ball cost? Please indicate your answer in cents. (Intuitive answer: 10 / Correct answer: 5)

2) If it takes 5 machines 5 minutes to make 5 widgets, how long would it take 100 machines to make 100 widgets? Please indicate your answer in minutes. (Intuitive answer $100 /$ Correct answer: 5)

3) In a lake there is a patch of lily pads. Every day the patch doubles in size. If it takes 48 days for the patch to cover the entire lake, how many days would it take for the patch to cover half the lake? (Intuitive answer: 24 / Corect answer: 47)

4) A man buys a pig for 60 Euros, sells it for 70 Euros, buys it back for 80 Euros, and sells it finally for 90 Euros. How much has he made? Please indicate your answer in Euros. (Intuitive answer: $10 /$ Correct answer: 20) 
5) In an athletics team, tall members are three times more likely to win a medal than short members. This year the team has won 60 medals so far. How many of these have been won by short athletes? (Intuitive answer: 20 / Correct answer: 15)

6) If John can drink one barrel of water in 6 days, and Mary can drink one barrel of water in 12 days, how long would it take them to drink one barrel of water together? Please indicate your answer in days. (Intuitive answer: 9 / Correct answer: 4)

\section{Questionnaire}

1) Did you report your preferences truthfully, that is, in descending order of value?

2) How difficult was the choice you had to make in the assignment procedure? (1: very easy, 7: very difficult)

3a) If you had another chance in the assignment procedure would you act differently?

3b) Please briefly explain why / why not:

4) The explanation of the procedure made the task easier. (1: strongly disagree, 7 : strongly agree)

5a) Was there a best strategy for reporting preferences in the assignment procedure?

$5 b)$ If possible, please briefly explain this strategy:

6) You followed the best strategy. (1: strongly disagree, 7: strongly agree)

7) Did you take into account the following piece of information when submitting your application form? [Extract of instructions]

8) How satisfied are you with the outcome of the assignment procedure, that is, the university seat assigned to you? (1: very dissatisfied, 7: very satisfied)

9) How fair do you consider the outcome of the assignment procedure? (1: very unfair, 7: very fair)

10) How satisfied are you with the assignment procedure, that is, the rules used to allocate the university seats? (1: very dissatisfied, 7: very satisfied)

11) How fair do you consider the assignment procedure? (1: very unfair, 7: very fair)

12) To what extent was the assignment procedure explained thoroughly? (1: not at all,

7: completely) 
13) To what extent was the assignment procedure explained honestly? (1: not at all, 7 : completely)

14) To what extent was the assignment procedure explained accurately? (1: not at all, 7 : completely)

15) To what extent was the explanation of the assignment procedure comprehensible? (1: not at all, 7: completely)

16) How fair do you consider the information about the assignment procedure? (1: very unfair, 7: very fair)

17) To what extent did you trust the information about the assignment procedure? (1: not at all, 7: completely)

18) To what extent was the outcome of the assignment procedure predictable? (1: not at all, 7: completely)

\section{$\underline{\text { Demographics }}$}

1) Please indicate your age:

2) Please indicate your gender:

3) Are you an international student?

4) In which student program are you currently enrolled?

5) Have you ever applied for a seat via the SfH (hochschulstart.de), formerly the Central Authority for University Admission?

6) How many years of education have you completed (including primary, secondary, tertiary)?

7) In how many experiments have you participated?

8) What were your impressions of this experiment (comprehension problems, positive aspects, negative aspects)?

\section{Control Questions}


1) Suppose you have been assigned Type 1 . How many other Type- 1 students are in your group? [2]

2) Suppose you have been assigned Type 2. Do universities grant you a priority over Type-1 students? (Yes/No/I don't know) [No]

3) Suppose you have been assigned Type 1. Do universities grant you a priority over the other Type-1 students? (Yes/No/I don't know) [I don't know]

4) Suppose you have been admitted at university B. How many points do you earn? [67]

5) Does your valuation of university seats depend on whether you have been assigned Type 1 or Type 2? (Yes/No/I don't know) [No] 